${ }^{1} 20,8$

$-M 691 e$

No.45

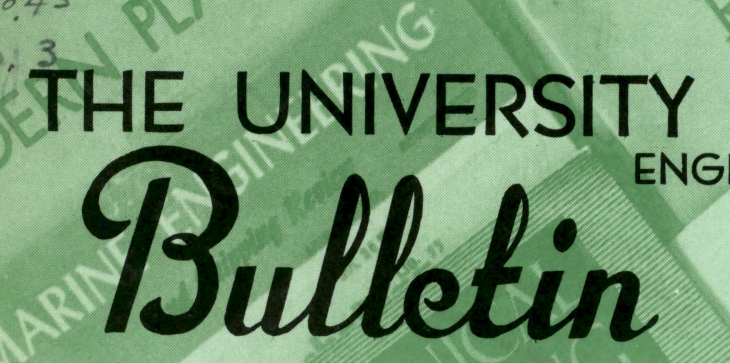

OF MISSOURI INEERING REPRIND SERIES

Reprint Number 45

Engineering Experiment Station Columbia, Missouri

\title{
PRESSURE CHANGES AT OPEN JUNCTIONS
}

\section{IN CONDUITS}

\section{Reprinted from}

Journal of the Hydraulics Division, Proceedings of the American

Society of Civil Engineers, 2057, June, 1959, HY6.

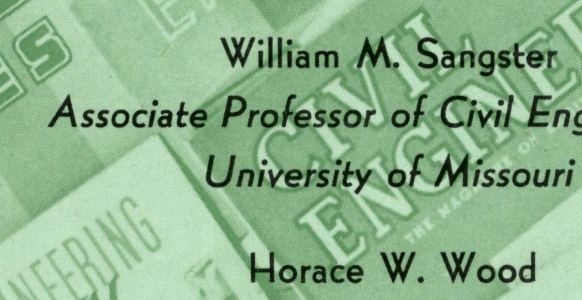

Professor and Chairman of Civil Engineering

University of Missouri

Ernest T. Smerdón Instructor in Civil Engineering - University of Missouri

Herbert G. Bossy Highway Research Engineer U.S. Bureau of Public Roads Washington, D.C. 


\title{
COLLEGE OF ENGINEERING \\ THE ENGINEERING EXPERIMENT STATION
}

The Engineering Experiment Station was organized in 1909 as a part of the College of Engineering. The staff of the Station includes all members of the Faculty of the College of Engineering, together with Research Assistants supported by the Station Funds.

The Station is primarily an engineering research institution engaged in the investigation of fundamental engineering problems of general interest, in the improvement of engineering design, and in the development of new industrial processes.

The Station desires particularly to co-operaie with industries of Missouri in the solution of such problems. For this purpose, there is available not only the special equipment belonging to the Station but all of the equipment and facilities of the College of Engineering not in immediate use for class instruction.

Inquiries regarding these matters should be addressed to

\author{
The Director, \\ Engineering Experiment Station \\ University of Missouri \\ Columbia, Missouri
}

\section{THE UNIVERSITY OF MISSOURI BULLETIN}

VOL. 60 , NO. 53

ENGINEERING REPRINT SERIES 1959, NO. 45

Published by the University of Missouri at Publications Office, Columbia, Missouri. Entered as second-class matter, January 2, 1914, at post office at Columbia, Missouri, under Act of Congress of August 24, 1912. Issued five times monthly. 
Journal of the

\title{
HYDRAULICS DIVISION
}

\section{Proceedings of the American Society of Civil Engineers}

\section{PRESSURE CHANGES AT OPEN JUNCTIONS IN CONDUITS}

\author{
William M. Sangster, ${ }^{1}$ A. M. ASCE; Horace W. Wood, ${ }^{2}$ M. ASCE; \\ Ernest T. Smerdon; ${ }^{3}$ and Herbert G. Bossy, ${ }^{4}$ M. ASCE
}

\section{SYNOPSIS}

This paper contains the results of an analytical and experimental investigation of the effects of open junctions on the magnitude of pressure changes in closed conduits flowing full. Junctions of rectangular, square, and round plan were studied.

Data concerning the performance of such junctions have been extremely meager in the past and designs have therefore been based on rather arbitrary procedures. The present paper furnishes data which afford the means for a rational hydraulic design of these structures.

\section{INTRODUCTION}

While the investigation reported herein was designed to furnish data specifically suited to the design of storm drain systems, it is believed that the results have a somewhat wider range of applicability. Hence, no attempt is made in this paper to restrict the discussion to any particular field of application.

Past practice has ascribed to open junctions in pipe systems an arbitrary yet small head loss. The authors have, however, determined that losses at such junctions may indeed be of an important magnitude. As a result, new methods of analysis have been proposed and old ones modified so as to provide a more realistic basis for design.

Note: Discussion open until November 1,1959 . To extend the closing date one month, a written request must be filed with the Executive Secretary, ASCE. Paper 2057 is part of the copyrighted Journal of the Hydraulics Division, Proceedings of the

American Society of Civil Engineers, Vol. 85, No. HY 6, June, 1959.

1. Associate Prof. of Civ. Eng., Univ. of Missouri; Columbia, Mo.

2. Prof. and Chmn. of Civ. Eng., Univ. of Missouri; Columbia, Mo.

3. Instructor in Civ. Eng., Univ. of Missouri; Columbia, Mo.

4. Highway Research Engr., U. S. Bureau of Public Roads; Washington, D. C. 
Because the designer is interested primarily in the variation of pressure throughout the system rather than in the variation of total head, the results are presented in terms of the changes in piezometric head prevailing at these junctions in preference to the more customary total head loss coefficients.

\section{General}

The shape of junction of primary interest to one of the sponsoring agencies, and therefore the one studied in greatest detail, was a rectangular one having a width-to-length ratio of 1 to 2.5. As a consequence, the analyses and tests applicable to such structures are presented first. A subsequent section extends the discussion to the more general cases of square and round junctions and, in addition, correlates these to the rectangular.

In order to identify each pipeline and the conditions therein a systematic subscript notation has been employed. The number " 1 " is reserved for conditions in the downstream pipe and the following larger numbers are assigned in order to conditions in the pipes met in turn in moving from the downstream pipe in a clockwise manner in the plan view.

So that the effect of the junction might be properly delineated, the established piezometric head lines in the various pipes were projected to the center of the junction so that any pipeline resistance losses would automatically be excluded from the pressure change attributable to the junction. The method of determination of the pressure change is described in detail in the following section.

\section{Experimental Methods}

\section{Test Equipment}

A general isometric view of the test equipment for a typical junction is presented in Fig. 1. Metered flows were supplied to Lucite model pipelines which were in turn connected to the model junction. The junction itself was constructed of Plexiglas plate.

Each of the header tanks indicated in Fig. 1, was supplied with a series of baffles, a rounded inlet for the pipeline, and a set of straightening vanes within the pipeline itself. The purpose of each of these appurtenances was to aid in obtaining fully established flow in as short a distance along the pipeline as possible. As a further means of ensuring normal velocity distributions in the pipes, all lines were made as long as was compatible with the physical dimensions of the laboratory. Lengths of at least 25 pipe diameters were employed, and in every case but one lengths of more than 40 diameters were used. Such lengths have beenstated $(1)$ to be sufficient for the development of fully established flow.

The outlet box and tail gate shown in Fig. 1 were provided for two purposes; viz., (1) to force all the pipes in the system to flow full, and (2) to permit variation of the depth of water in the junction.

Generally seven piezometers were connected to each of the model pipelines to define the slope of the piezometric head lines. These piezometers were concentrated most heavily at the downstream end of each pipe so that the slope of the piezometric head line in established flow might be determined. In addition a collection ring was attached to the model junction with several taps 


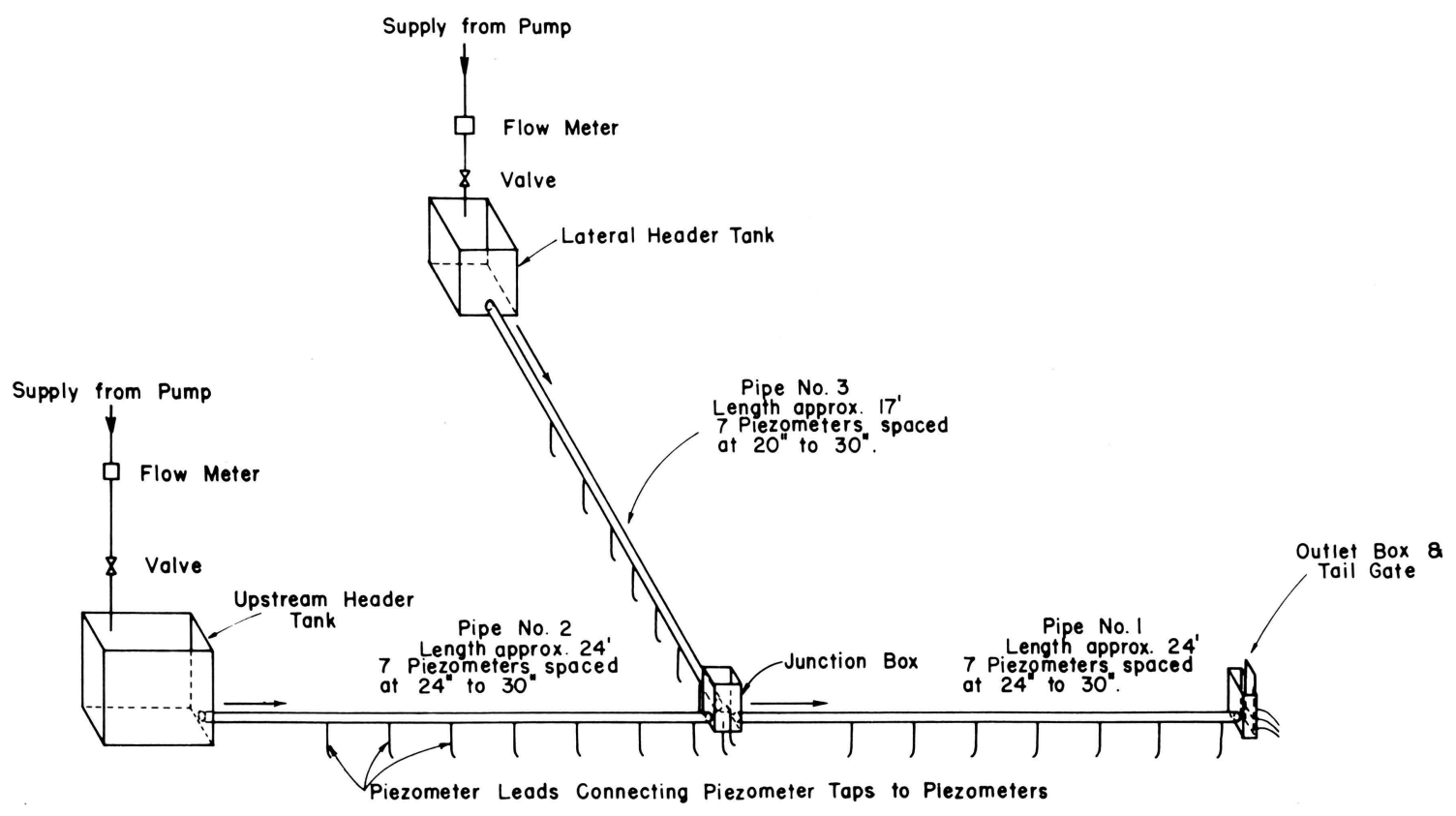

Fig. 1. General layout of model system. 
through the walls of the junction so that a measure of the average elevation of the free surface in the junction might be obtained.

Four sizes of Lucite pipe were used for the model pipelines; namely, 3.00, $3.75,4.75$, and 5.72 inches in inside diameter. Use of these sizes permitted variation of the relative size of the three pipelines and of the pipe size relative to the junction size, even though only a few absolute junction sizes were employed.

\section{Testing Procedure}

In practically all of the tests the end product of the testing was the determination of the change in piezometric head between each inflow pipe and the downstream pipe. This, of course, required careful establishment of the piezometric head line for each pipe. During the testing of certain configurations a considerable amount of surge was observed in the piezometers, in which case readings were taken so as to ascertain the extremes of this fluctuation and the average was then determined.

Determination of the slope of the piezometric head line for flow in the model was facilitated through use of standard resistance slopes. Tests were made at the beginning of the laboratory program on long sections of the model pipe to define the resistance slope for various rates of flow in two sizes of pipe, the 3.00-inch and 5.72-inch. Plotting the results of these tests on the usual resistance coefficient vs. Reynolds number graph disclosed that the Lucite pipe had a resistance only slightly greater than that of hydraulically smooth pipe carrying turbulent flow. This conclusion is in substantial agreement with that reached by other investigators. (2) This higher value was caused mainly by non-uniformities in the pipe section and diameter, even though the walls were smooth. Once the resistance coefficients for these two sizes had been determined, curves of resistance slope vs. discharge rate for each of the four pipe sizes were prepared, it being known that the temperature of the water in the recirculating system would be nearly constant. These resistance slopes were computed through use of the Darcy-Weisbach equation.

In order to investigate the effect of the total rate of flow and to ensure the accuracy of the test results, each configuration was tested with at least two different total discharges and two different depths of water in the junction.

\section{Treatment of Test Data}

The initial step in interpretation of the test data was the plotting of the piezometer readings against the location within the system of the corresponding piezometer taps. The plotted points thus represented the location of the piezometric head lines for each of the various pipes of the test arrangement. Straight lines representing the standard resistance slopes described previously were fitted to the plotted points in order to eliminate any error which might be caused by the incorrect elevation of any single point. The greater weight in the determination of the position of the piezometric head line was accorded the points nearer the downstream end of each pipe. In the upstream portion of the pipes the measured pressure elevations were found to lie somewhat above these lines due, of course, to the fact that the normal velocity distribution had not been fully developed in this section.

The determination of pressure changes across the junction required the measurement of the vertical distance between the plotted upstream and downstream pressure lines, each projected to some common vertical plane or line. 
For convenience in design the point of intersection of these pipe centerlines at the centerline of the box was selected as the point of reference. These points are called "branch points" after McNown.(3)

For convenience of application to design, the measured pressure changes were plotted in their ratio to the mean velocity head in the downstream pipe thus producing a dimensionless coefficient.

\section{Rectangular Junction with Main and Lateral}

This pipe arrangement consisted of a through line and a pipe aligned perpendicularly to this main or through line entering the narrow side of the junction as indicated in plan in the insets in Figs. 2 and 3. The flowlines of all the pipes were flush with the junction floor since an early series of tests indicated negligible differences between the cases of flowline and crownline alignment.

Pipes perpendicular to the downstream pipe occur frequently in the discussions of this configuration and of those which follow; hence, for simplicity they will be referred to subsequently as "laterals". Laterals, when used, carried flow to the junction and only one downstream pipe was included in any of the systems.

In this series of tests the downstream pipe generally had a flush, squareedged entrance at the junction box, although a few runs were made to ascertain the effect of other entrance conditions. In these additional tests rounded and projecting entrances of types discussed later were investigated.

In combining flow such as that being discussed, the downstream pipe should ordinarily be larger than any upstream pipeline, so that values of the diameter ratios $D_{1} / D_{2}$ and $D_{1} / D_{3}$ equal to or greater than unity were the only ones tested. Only two sizes of pipe were employed for the downstream pipe; viz., the 4.75-inch and 5.72-inch diameters. $\mathrm{D}_{1} / \mathrm{D}_{2}$ values of $1.00,1.20,1.58$ and 1.91 ; and $D_{1} / D_{3}$ values of $1.00,1.20,1.53,1.58$, and 1.91 were tested.

For this arrangement of pipes it was to be expected that the momentum of the flow from the upstream main would be preserved to some extent in crossing the junction and would aid in maintaining flow in the downstream pipe. On the other hand, the momentum of the flow in the lateral should be anticipated to be relatively ineffective in supporting the flow in the downstream pipe, at least at the lesser rates of flow. The flow from the lateral thus should be considered as a mass of fluid which must be merged with and carried along by the flow from the upstream main. As a consequence, the pressure at the exit from the lateral should be expected to be the same as that at the exit from the upstream main. Also, the upstream pressure lines projected to the branch point should be at roughly the same elevation as the water surface in the junction, since the box pressure is the source of one force which maintains the flow in the downstream pipe. In cases in which small laterals carry large rates of flow with resulting high velocities, the lateral jet should disrupt the flow from the upstream main, requiring higher pressures in the junction. Moreover, it is evident that, whenever the pressure at the exits from the upstream main and from the lateral are not greatly different, an analysis for $\mathrm{K}_{2}$, the pressure change coefficient for the upstream main, will also be applicable with satisfactory accuracy to the valculation of $\mathrm{K}_{3}$, the pressure change coefficient for the lateral. This situation should occur when a relatively small proportion of the total flow in the system enters from the lateral. 

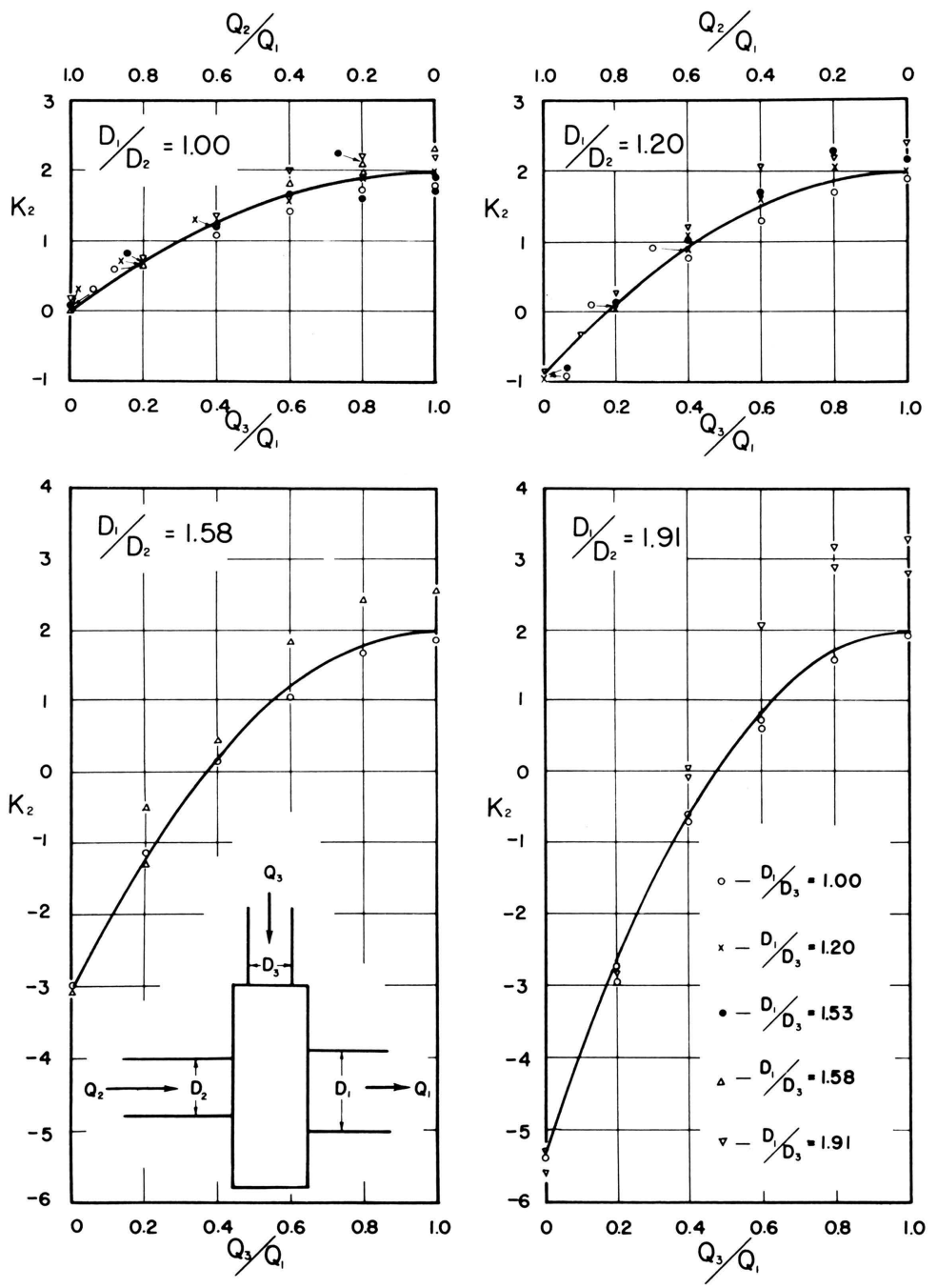

Fig. 2. $\mathrm{K}_{2}$ for in-line system with $90^{\circ}$ lateral. 

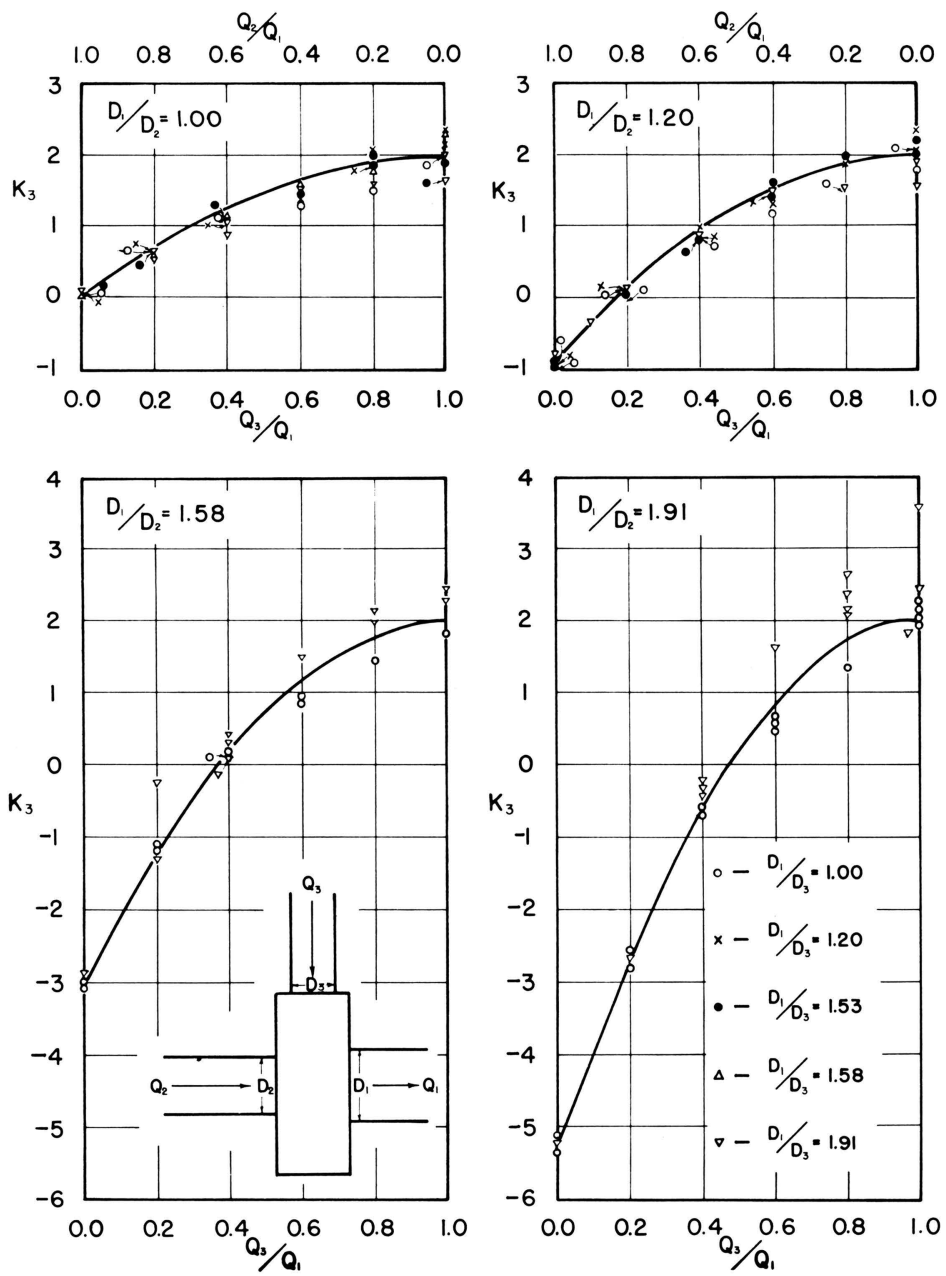

Fig. 3. $\mathrm{K}_{3}$ for in-line system with $90^{\circ}$ lateral.

Theoretical Analysis

A method of analysis involving the momentum concept is useful in this case. As noted earlier, it seems logical to assume that the flow from the upstream main contributes the only momentum effective in the direction of the downstream flow, and that the flow from the lateral furnishes an added mass to be carried into the downstream pipe by the force of the box pressure. An analysis based on this foundation should be expected to be least accurate in those cases in which the lateral efflux velocity is high enough to cause the jet from the lateral to impinge on or penetrate that from the upstream main, thereby causing both to be deflected and diffused with an attendant increase in the level of pressure in the box required to maintain flow. 
Continuity in this case requires that

$$
Q_{1}=Q_{2}+Q_{3}
$$

in which $\mathrm{Q}$ is the volume rate of flow, and the identifying subscripts are as discussed earlier.

The momentum equation for expanding flow incorporating the assumptions described previously is

$$
r h_{2}^{\prime} A_{2}-r h_{1}^{\prime} A_{1}+\gamma h_{2}^{\prime}\left(A_{1}-A_{2}\right)=Q_{1} \rho V_{1}-Q_{2} \rho V_{2}
$$

in which $\gamma$ is the specific weight of the fluid, $h^{\prime}$ is the piezometric head, $\mathrm{A}$ is the cross-sectional area of flow, $\rho$ is the fluid density, and $\mathrm{V}$ is the mean velocity of the flow. The piezometric heads appearing in Eq. (2) are obtained by projecting the piezometric head lines to the branch point.

Combining Eqs. (1) and (2), and simplifying

$$
h_{2}=h_{2}^{\prime}-h_{1}^{\prime}=2 \frac{V_{1}^{2}}{2 g}\left[1-\left(\frac{\varphi_{2}}{Q_{1}}\right)^{2}\left(\frac{A_{1}}{A_{2}}\right)\right]
$$

Defining $\mathrm{K}_{2}=\frac{h_{2}}{V_{1} 2_{2} / 2 g}$, Eq. (3) may be transformed into

$$
K_{2}=2\left[1-\left(\frac{Q_{2}}{Q_{1}}\right)^{2}\left(\frac{D_{1}}{D_{2}}\right)^{2}\right]
$$

wherein D is the pipe diameter. Eq. (4) is the fundamental equation for determining pressure changes in this particular system. As noted previously, it may be used unchanged to obtain $\mathrm{K}_{3}$ so long as the lateral introduces only a relatively small portion of the total flow.

\section{Test Results}

While the division of flow rates between the lateral and the upstream main is a primary variable, it is obvious that the same division may be obtained with any number of total rates of flow. In order that the effect of the total rate might be determined, at least two values of the total flow were tested for each flow division and geometry. On the basis of many hundreds of tests the conclusion seemed appropriate that the value of the total flow rate exerted only a negligible and unsystematic influence on the pressure change coefficients once the geometry and flow division were fixed.

To examine the agreement between test and analysis Figs. 2 and 3 are provided on which Eq. (4) is represented by the solid curves. The trend of the data is quite apparent. Almost exact agreement between analysis and test exists from $Q_{3} / Q_{1}=0$ to the flow division at which $K_{2}$ or $K_{3}$, as the particular case may be, is zero. This, of course, occurs when the momenta of the flow in the upstream and downstream mains are equal, since the quantity $\left(\frac{Q_{2}}{Q_{1}}\right)^{2}\left(\frac{D_{1}}{D_{2}}\right)^{2}$ in Eq. (4) is the ratio of these momenta. It is further evident that beyond the flow division for which $\mathrm{K}$ is zero the equation gives a fairly good average value of the test points. When the lateral and downstream pipes are of relatively the same size, the agreement extends nearly through the entire range of flow divisions. Only when small laterals are employed (with consequently large values of the lateral momentum) does the deviation become appreciable. As a consequence Eq. (4) can be depended upon when $Q_{3} / Q_{1} \leq 0.4$ for any geometry and for all values of $Q_{3} / Q_{1}$ when the lateral and downstream pipe 
sizes are nearly equal, provided the junction box is rectangular and of considerable length in relation to the downstream pipe diameter.

Since the size and shape of the junction should be expected to modify the pressure changes when a large part of the total flow is from the lateral, it is obvious that Eq. (4) should be applied only to junctions which are geometrically similar to the one tested; i.e., to a rectangular junction. Even for these junctions the equation produces less reliable results for smaller size laterals carrying disproportionate shares of the total flow. Square and round junctions are discussed later.

\section{Effect of Downstream Pipe Entrance Conditions}

The effect of entrance conditions at the downstream pipe was also investigated for this system. In addition to the square-edged, flush entrance utilized in the majority of the tests, two other entrance types were tested. One was a square-edged projecting pipe with a wall thickness of $1 / 12$ the downstream pipe diameter extending into the box $1 / 4$ the box width. The other was a flush entrance with the edge rounded to a radius of $1 / 8$ the downstream pipe diameter.

In Fig. 4 the data showing the effect of entrance conditions on $\mathrm{K}_{2}$ and $\mathrm{K}_{3}$ for the two pipe-size combinations tested are assembled. The re-entrant condition is seen to have a negligible effect on lateral or upstream-main pressure throughout the entire range of flow divisions, except when small laterals carry almost all the flow, a condition not likely to be encountered. The rounded entrance, on the other hand, does exhibit a measurable reduction in $\mathrm{K}_{2}$ and $\mathrm{K}_{3}$ in the range of flow divisions producing positive pressure changes. The degree of reduction of the lateral pressure due to rounding the downstream entrance is almost exactly duplicated in the upstream main.

On the basis of these results it would appear that efforts to improve the downstream entrance conditions can produce minor benefits, but only in the range of flow divisions involving high proportions of lateral flow. It is also clear that reasonable projections of the downstream pipe are not detrimental.

\section{Through Line Only}

Many tests were run on a rectangular junction with an upstream and downstream main aligned in plan and with no lateral present. Two cases were recognized in these investigations; viz., expanding and contracting flow.

\section{Expansions}

With an expansion of flow the analysis leading to Eq. (4) applies in this case also, except that $Q_{1}=Q_{2}$. Thus

$$
K_{2}=2\left[1-\left(\frac{D_{1}}{D_{2}}\right)^{2}\right]
$$

\section{Contractions}

The primary difference in the analysis of contractions as compared with that for expansions involves the application of the momentum principle between the contracted section just inside the downstream pipe and a section further downstream at which the flow has expanded to again fill the pipe. Losses due to boundary separation occur almost exclusively in the zone 

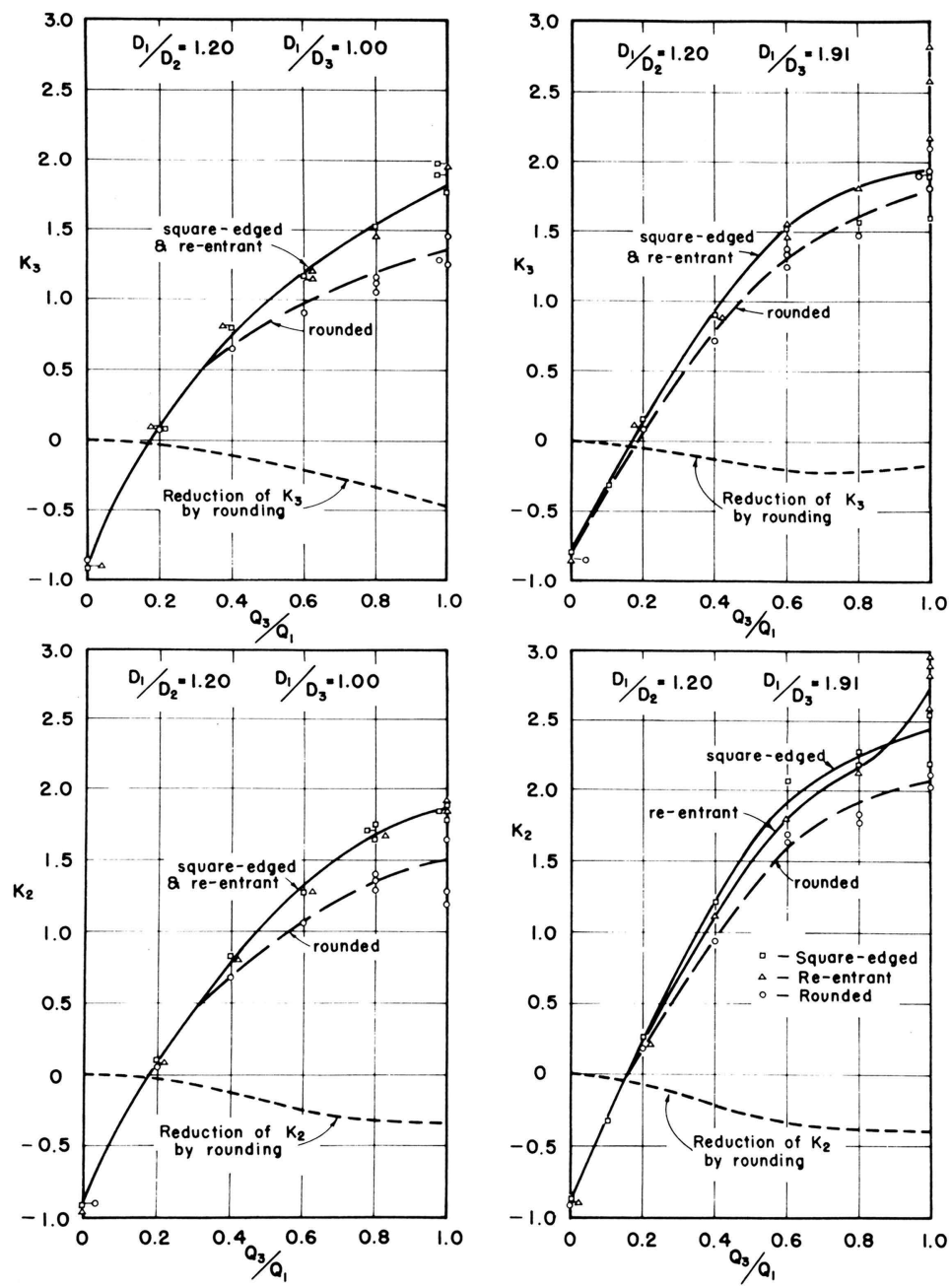

Fig. 4. Effect of projecting and rounded entrances to downstream pipe.

following the section of greatest contraction of the flow (where conditions are denoted by the subscript c). As in the case of expansions, inclusion in the final equation of losses due to surface resistance is circumvented by projecting the piezometric head lines to the branch point.

Continuity requires that

$$
Q_{1}=A_{1} V_{1}=Q_{c}=A_{c} V_{c}=Q_{2}=A_{2} V_{2}
$$

The momentum principle can be applied between sections $\mathrm{c}$ and 1 (downstream) to yield

$$
\gamma h_{c}{ }^{\prime} A_{1}-\gamma h_{1}^{\prime} A_{1}-e=Q_{p}\left(V_{1}-V_{c}\right)
$$


in which $\mathbf{R}$ is the boundary shear force in the pipeline between sections $\mathrm{c}$ and 1 and the ( $h^{\prime}$ )'s in this case are the piezometric heads at sections $c$ and 1. Eq. (7) is true by virtue of the fact that the piezometric head at section $c$ must be constant completely across the section of area $A_{1}$, since the streamlines of the submerged jet are parallel there. Eq. (7) combined with Eq. (6) reduces to

$$
h_{c}^{\prime}-h_{1}^{\prime}-\frac{R}{r A_{1}}=\frac{1}{g A_{1}}\left[V_{1}^{2} A_{1}-V_{c}^{2} A_{c}\right]=2 \frac{V_{1}^{2}}{2 g}\left[1-\frac{1}{c_{c}}\right]
$$

in which $\mathrm{C}_{\mathrm{c}}$ is the ordinary contraction coefficient. (4)

The Bernoulli or energy equation written between sections 2 and $\mathrm{c}$, in which region a small resistance loss, $\mathrm{H}_{\mathrm{f}}$, occurs, gives rise to

$$
h_{c}^{\prime}+\frac{V_{c}{ }^{2}}{2 g}=h_{z}{ }^{\prime}+\frac{V_{2}^{2}}{2 g}-H_{f}
$$

Combination of Eqs. (8) and (9) leads to

$$
h_{2}{ }^{\prime}-h_{1}^{\prime}-\frac{R}{r A_{1}}-H_{f}=\frac{V_{1}^{2}}{2 g} \frac{1}{C_{c}{ }^{2}}-\frac{V_{1}^{2}}{2 g} \frac{A_{1}^{2}}{A_{2}^{2}}+\frac{V_{1}^{2}}{2 g}+\frac{V_{1}^{2}}{2 g}\left[1-\frac{2}{C_{c}}\right]_{1}
$$

If the piezometric head lines are projected to the branch point, the left side of Eq. (10) is approximately $\mathrm{h}_{2}$. The only discrepancy is the difference in the resistance slopes for the two pipes multiplied by the distance between the junction centerline and the contracted section. This is obviously of secondary importance.

Inserting the diameters $D_{1}$ and $D_{2}$, and $K_{2}=\frac{h_{2}}{V_{1}^{2} / 2 g}$ into Eq. (10) results in

$$
K_{2}=1-\left(\frac{D_{1}}{D_{2}}\right)^{4}+\left(\frac{1}{C_{c}}-1\right)^{2}
$$

Eq. (11) is the desired formula for the pressure change coefficient for contractions in a two-pipe system.

\section{Test Results}

Either of Eqs. (5) or (11) should be applicable to the analysis of flow in equal-size pipes. Both equations yield zero for $\mathrm{K}_{2}$, while the experiments indicate a positive but small value for this coefficient. It should be pointed out that in the derivation of the two equations mentioned, the junction width, $b$, was considered to be negligible; i.e., the entire unit was assumed to behave as a sudden expansion or contraction, as the case may be. Still it seems reasonable that at some large value of the parameter $b / D_{2}$ the jet will not remain essentially intact while crossing the junction, and a consequently larger loss will occur. This increase is due in part to viscous shear, but results primarily from the impingement of the spreading jet on the wall surrounding the entrance to the downstream pipe.

To test this hypothesis configurations having values of $b / \mathrm{D}_{2}$ up to 3.33 were investigated with equal size upstream and downstream pipes. Fig. 5 presents the results of these tests. The effect of increasing junction width seems to be a fairly uniform increase in $\mathrm{K}_{2}$, although it appears likely that some limiting value will be attained as the junction box is further enlarged. Definition of this limit was not attempted since the ratio of the distance across the box to the inflow pipe diameter was already near the upper end of the range likely to be encountered in practice. 


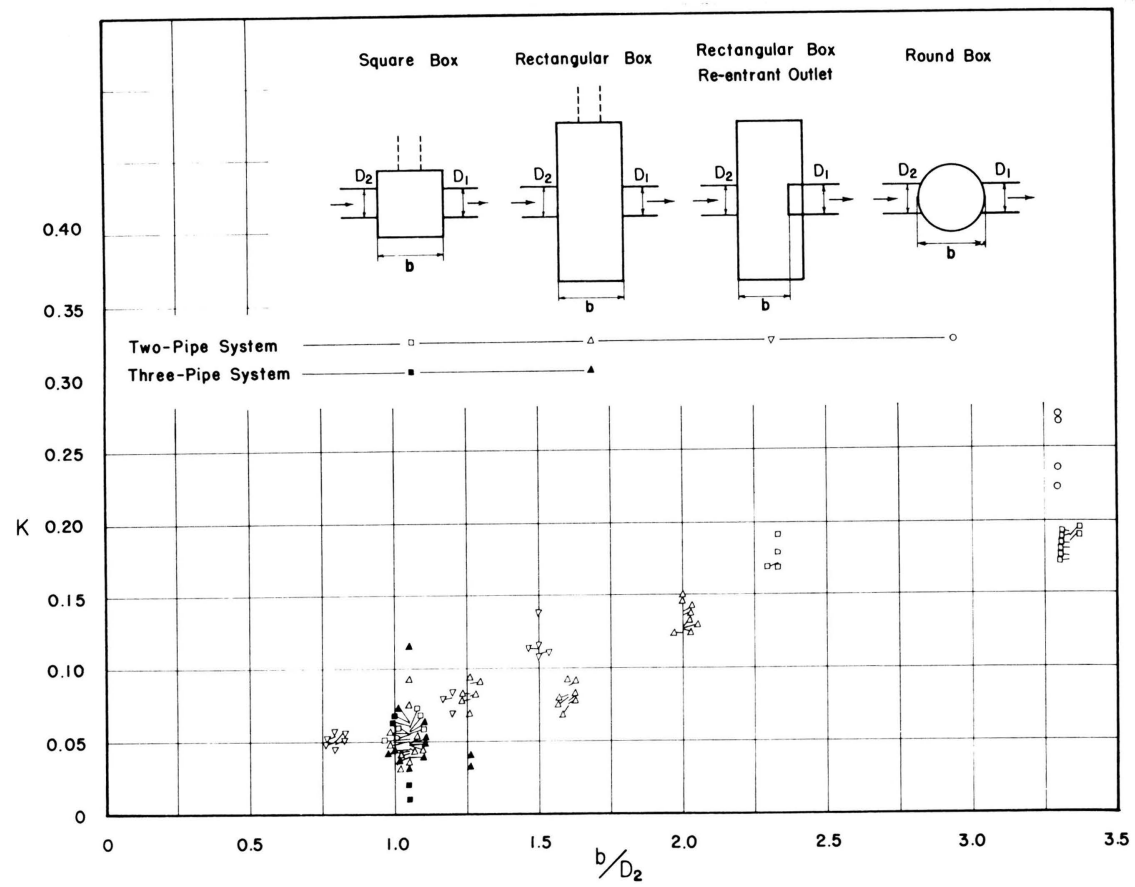

Fig. 5. Effect of junction width for equal-size pipes.

A series of tests was made with the available model pipes providing several ratios of upstream to downstream pipe sizes, and thus various degrees of expansion of the flow across the rectangular junction first described. The test results were compared to the theoretical analysis embodied in Eq. (5).

In Fig. 6, Eq. (5) is shown as a solid curve in the area of negative changes of pressure and the pressure change coefficients derived from the test data are plotted and suitably identified. Obviously the conformity between analysis and experiment is quite satisfactory. The large negative values are easily explained if it is recalled that the coefficients represent pressure changes and not changes in total head. Thus negative coefficients corresponding to pressure rises are to be expected whenever the fluid is caused to decelerate. In the present case this is brought about by the increase in pipe diameter on the downstream side of the junction.

Similar tests were made with various degrees of contraction of the flow across the same junction, and the results compared to the theoretical analysis expressed in Eq. (11).

In Fig. 6, Eq. (11) is shown as a dashed curve in the area of positive changes of pressure. The experimental pressure change coefficients for this case are also plotted for comparison. It is seen that the conformity between analysis and experiment is also satisfactory for contractions of flow.

Probably the most significant conclusion to be reached from the tests just described is the absence of effect of the box itself-at least for the range of the parameter $\mathrm{b} / \mathrm{D}_{2}$ tested. Thus, it would be expected that variations of construction details at the junction would not be effective in modifying its characteristics. However, the more common construction details were investigated. 


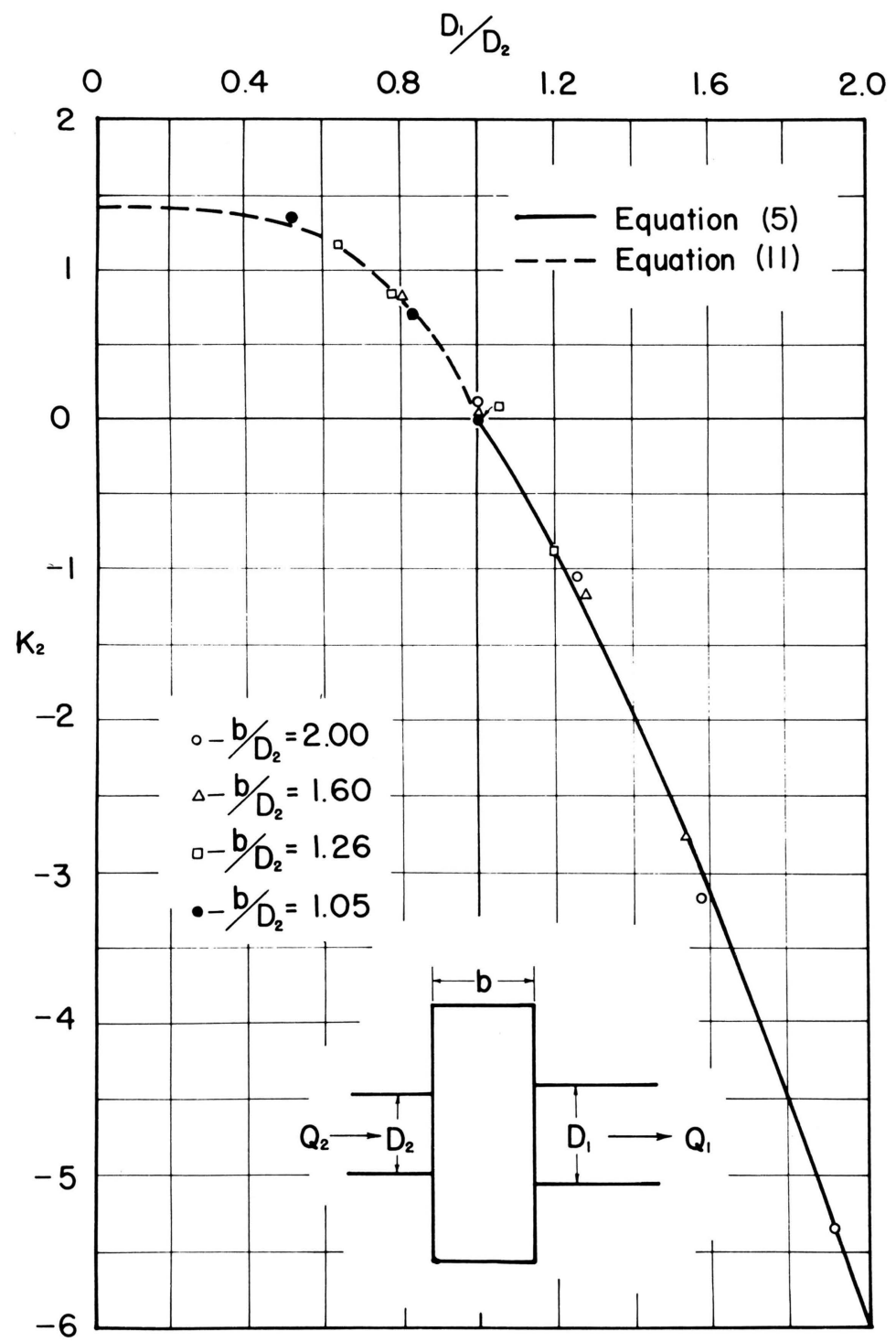

Fig. 6. Results for two-pipe in-line system. 
As was mentioned earlier, the vertical positioning of the pipe centerlines is immaterial so long as they are parallel and are aligned between limits in which either their crownlines or flowlines coincide.

In expansions of flow, it may be expected that the relatively short distances across the junction will result in the expansion taking place in the downstream pipe. Therefore, flowline or crownline alignment, downstream pipe projecting into the junction box, or rounding of the entrance to the downstream pipe should all be of negligible importance in modifying the pressure change coefficients. These conclusions were verified.

It seems reasonable that shaping of the bottom of the junction so as to continue a portion of the pipe section through the box can effect no significant improvement of the pressure change in straight-through flow. Although this inference was not tested, the latitude for possible reduction of loss is small.

Although rounding of the downstream entrance was not tested with contracting flow, it is evident that such rounding will reduce the pressure change coefficients because the loss at contractions is primarily due to constriction of the flow at the change in pipe size coupled with the subsequent expansion of the flow in the downstream pipe.

\section{Rectangular Junction with Opposed Laterals}

In this arrangement two lateral pipes were joined to the junction at the center of the long side of the junction as indicated in plan in the inset in Fig. 7. As before, the flowlines of all pipes were set flush with the bottom of the junction. The downstream pipe was fitted with a flush, square-edged entrance in every case.

\section{Theoretical Analysis}

As often occurs, the analysis of this configuration was suggested and guided by the results of the test program.

In every case the pressure change coefficients for one lateral appeared to have a reasonably constant value over a considerable range of flow divisions. The extent of this range seemed to be controlled by the relative magnitudes of the velocities in the two laterals. For all the combinations investigated, the first deviation of $\mathrm{K}$ from this constant value was perceptible when the velocity in the line with constant $\mathrm{K}$ became less than that in the line opposite. Thus $\mathrm{K}_{2}$ deviated from its constant value when $\mathrm{V}_{3} \geq \mathrm{V}_{2}$, and $\mathrm{K}_{3}$ when $\mathrm{V}_{2} \geq \mathrm{V}_{3}$. From this it was deduced that the coefficient pertaining to a particular pipe was controlled more by the flow in the pipe opposite than it was by the flow in the pipe itself.

A rational explanation of the two phenomena just noted can be attempted if it is realized that the pressure rise in the lateral carrying the lesser-velocity flow must be due to the force of the opposing jet. To aid in visualizing the forces, the action can be likened to a situation in which a vertical flat plate divides the junction box in a direction normal to the centerlines of the incoming laterals in such a way as to deflect the two jets. The resultant of the distributed pressure along this plate due to one of the jets may be considered to be linearly proportional to the jet velocity head.(5) The net force exerted on the plate is the difference between the forces exerted by the two jets and may be considered as transmitted to the fluid and eventually to the wall of 


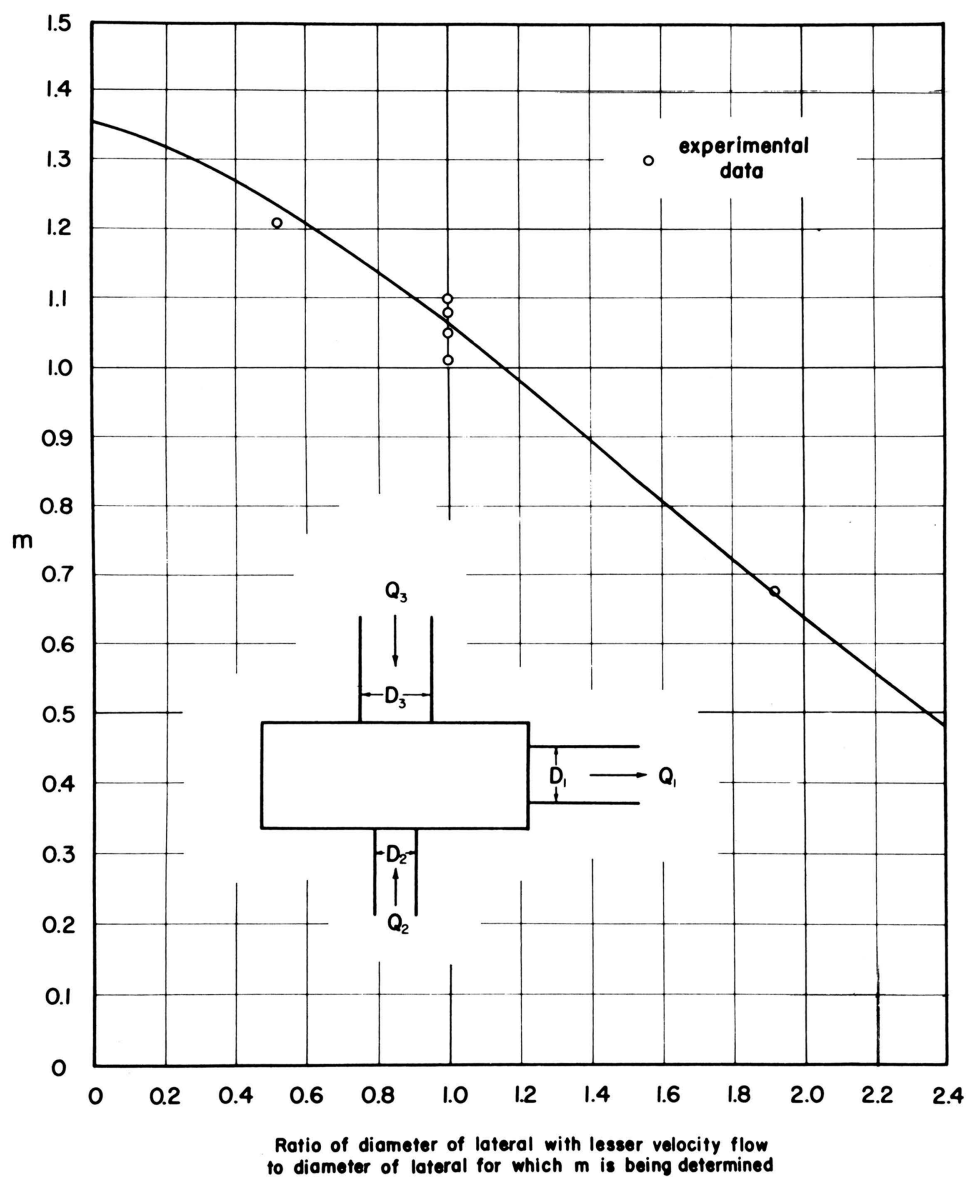

Fig. 7. Relative mean pressure coefficients for in-line opposed laterals.

the junction. The pipe having the lesser-velocity flow will be affected by this pressure differential over its entire area.

The final particular to be scrutinized in connection with the tests concerns the magnitude of the relatively constant values which $\mathrm{K}_{2}$ and $\mathrm{K}_{3}$ exhibited when $V_{2} \geq V_{3}$ and $V_{3} \geq V_{2}$, respectively. Precisely at the point where $\mathrm{V}_{2}=\mathrm{V}_{3}, \mathrm{~K}_{2}$ and $\mathrm{K}_{3}$ both approached 1.6 in value for all the conformations investigated in this series of tests. Thus 1.6 might be taken as a "base" value for the pressure change coefficients.

An attempt is made in the following to combine the significant facts just outlined into a mathematical analysis of the situation.

Utilizing a notation comparable to those previously employed, and assigning the higher velocity to lateral pipe 2, an expression embodying the $f$ undamental deduction from the experiments may be written

$$
h_{3}{ }^{\prime}-h_{2}{ }^{\prime}=m_{2} \frac{V_{2}{ }^{2}}{29}-m_{3} \frac{V_{3}{ }^{2}}{29}
$$


in which $\mathrm{m}$ might be referred to as a "mean pressure coefficient" and the piezometric head lines have again been projected to the branch point. The value for $m$ for a given pipe is fixed by the ratio of the pipe size to the size of the low-velocity lateral. The means by which $\mathrm{m}$ may be determined will be discussed later. Addition and subtraction of $h_{1}^{\prime}$ on the left side of Eq. (12) and division by the outfall velocity head results in the equation

$$
K_{3}-K_{2}=\frac{n_{3}-n_{2}}{V_{1}^{2} / 2 g}=m_{2}\left(\frac{Q_{2}}{Q_{1}}\right)^{2}\left(\frac{D_{1}}{D_{2}}\right)^{4}-m_{3}\left(\frac{Q_{3}}{Q_{1}}\right)^{2}\left(\frac{D_{1}}{D_{3}}\right)^{4}
$$

Assuming that $m_{2}$ and $m_{3}$ can be estimated, Eq. (13) still appears to contain two unknowns, $\mathrm{K}_{2}$ and $\mathrm{K}_{3}$. However, use may be made of the second fundamental observation discussed previously; viz., the constancy of the coefficients at a value of 1.6 until the velocity in the opposing lateral exceeds that in the lateral under consideration. Thus Eq. (13) permits calculation of the variable one of the two coefficients once $m_{2}$ and $m_{3}$ are known.

To determine the mean pressure coefficients Fig. 7 is presented. This figure presents the mean pressure (written in terms of the velocity head in the lateral from which the jet issues) exerted by a circular jet over any nearly concentric circular area of a plate held normal to the jet. This is restricted to the zone within which the flow is appreciably curved by the deflection. The curve was prepared on the basis of a general knowledge of the distribution of pressure exerted by a jet together with experimental substantiation.

The end points of the curve were based on values given in the reference literature. A value of $\mathrm{m}$ at the lateral-diameter ratio of zero can be approximated by the stagnation pressure corresponding to the maximum velocity, which occurs at the center of the lateral pipe. Rouse(6) gives an equation for the centerline velocity

$$
\frac{V_{\text {max }}}{V_{\text {mean }}}=1.43 \sqrt{f}+1
$$

in which $f$ is the Darcy friction factor. In the tests under consideration the average value of $f$ was 0.018 ; accordingly $m=1.42$. A value slightly lower than this was finally adopted in order to obtain better agreement with the experimental data.

At the other extreme Powell proposes a value of $m=0.33$ for the case in which the pressure is distributed over the entire area within which the flow is sensibly curved. He suggests that this area is 6 times that of the issuing jet. This value of $\mathrm{m}$ is less than the corresponding value indicated in Fig. 7 . However, the bottom of the junction box restricts the expansion of the jet in that direction and the average pressure head (which, in effect, is equivalent to $\mathrm{m} \frac{\mathrm{V}^{2}}{2 \mathrm{~g}}$ ) is thereby increased over that obtaining with a symmetrically expanding jet. Thus the higher value in Fig. 7 should be expected.

For a diameter ratio of unity, m must be approximately equal to the kinetic energy correction factor for the lateral flow, which in this case is roughly 1.05 .

In order to determine the shape of the curve between these three values, recourse was had to the experimental data. Substitution of the test results into Eq. (13) for a given geometry and with all the flow through one lateral yielded the value of $\mathrm{m}$ for that lateral. The results of the calculations from the experimental data and the pseudo-theoretical curve are presented in Fig. 7. 
Test Results

Eq. (13) is plotted in Fig. 8 together with the applicable experimental points. The correlation is clearly very good throughout the entire range of pipe-size ratios and flow divisions tested. In this regard it is appropriate to note that the one set of tests involving unequal-size laterals represents conditions as greatly different from equal-size laterals as was possible with the equipment available. Since Eq. (13) is substantiated for $D_{2} / D_{3}=0.524,1.00$, and 1.91 , it is reasonable to assume that it is also valid for intermediate conditions.

To be noted in Fig. 8 are the large values of the coefficients accompanying substantially different velocities in the two laterals. Thus when unequal velocities in the two laterals are anticipated or may occur, adoption of this arrangement of pipes should be carefully evaluated. Means of avoiding large losses with directly-opposed laterals are discussed in the following.
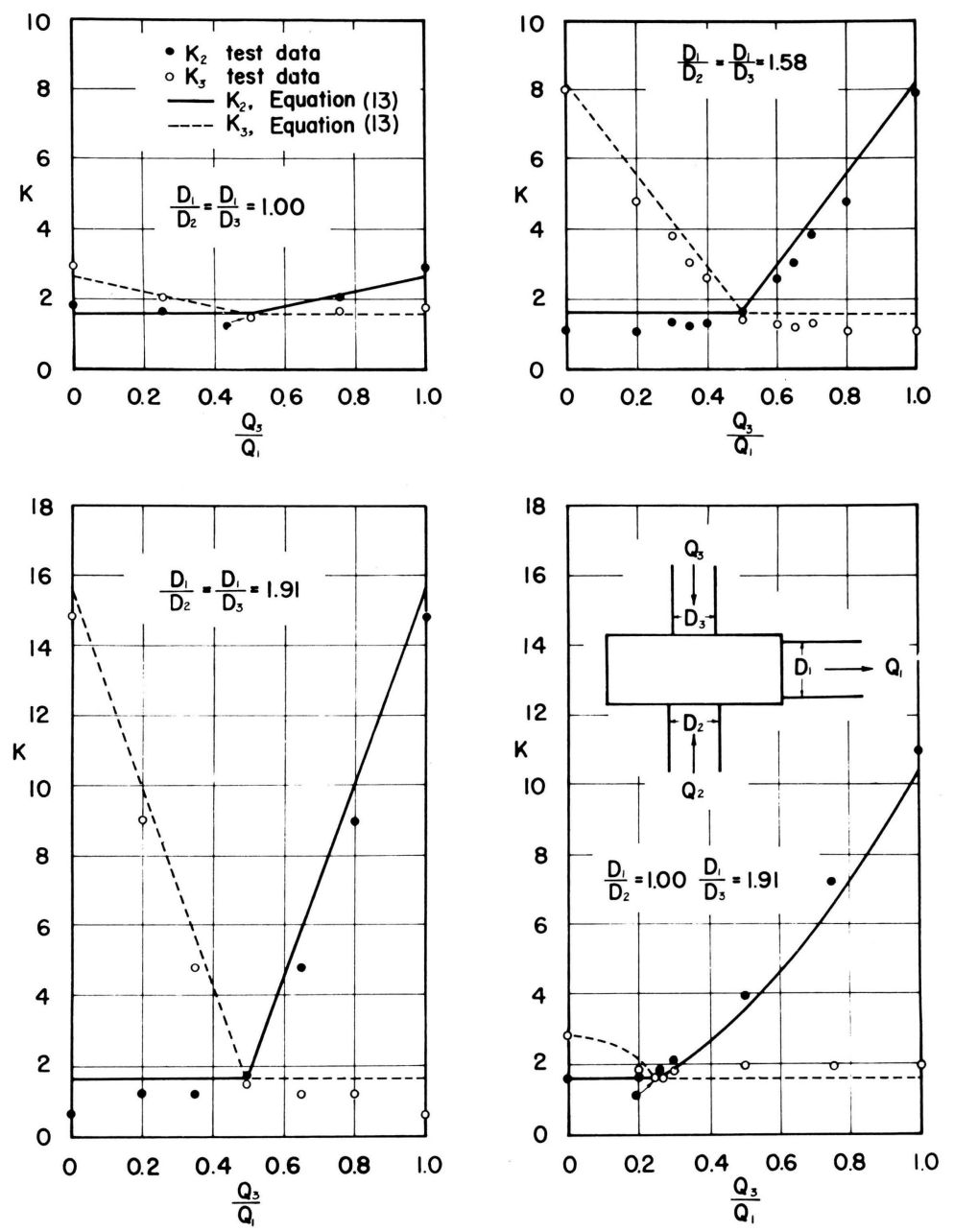

Fig. 8. Results for in-line opposed lateral system. 
Improving Opposed-Lateral Flow

Offset Laterals. - Simply offsetting the laterals in plan as indicated in the inset in Fig. 9 proved to be the most effective way of improving the flow characteristics of opposed-lateral flow with rectangular junctions. On the basis of the tests and on consideration of the area over which significant pressures are exerted by a deflected jet, it was concluded that to be most effective the offset of the lateral centerlines should be at least equal to the sum of the lateral diameters.

In Fig. 9 the experimental data on the offset laterals are presented. It will be immediately remarked that the losses were reduced considerably as compared with the directly-opposed laterals. In these tests the pressure change coefficients were always below 2.5 times the outfall velocity head, and generally were below 2.0. Perhaps even more important, the coefficients varied between very narrow limits throughout the practical range of flow divisions. Thus by simply realigning the pipes a material increase in the flow efficiency of the junction box was realized.

No analytical solution for pressure changes at this type of junction is presently available.

Deflector Devices. - Several deflector devices, incorporating deflecting and guiding walls, were added to the offset-lateral system in an attempt to further improve the hydraulic characteristics of this configuration.

The deflector devices used were of two basic types. In one a wall across the corner of the junction was used to deflect the flow from the far lateral toward the downstream pipe. It was realized that the deflected flow would follow the far wall of the junction box, and thus tend to pass across the exit from the near lateral, with the possible effect of increasing the pressure level in the near lateral. A second type, with a curved deflector across the far lateral terminating in a wall extended to the near lateral, was evolved to avoid this possible adverse effect.

An over-all appraisal of the deflector devices tested would be that in general they effected some reduction in the pressure change coefficients. However, it is believed, on the basis of the present investigation, that the improvement in the hydraulic characteristics of the junctions with offset laterals, brought about by the use of deflecting and guiding walls, is so slight as to make their use unwarranted without further study in most cases.

\section{Square and Round Junctions}

Since in this paper consideration is given only to cases in which all pipes flow full, changes in pipeline grade may be neglected. The testing of square and round junctions was limited to studies of three-pipe systems consisting of upstream and downstream mains, and a lateral at $90^{\circ}$ to these mains. Primary attention was directed toward situations in which most of the flow was carried by the lateral, since it had been found during the investigation of the rectangular junction that the relative size of the lateral pipe and the size and shape of the junction were necessarily ineffective so long as the momentum of the flow in the upstream main was greater than that in the downstream pipe.

The tests revealed that the magnitude of the pressure changes at various divisions of flow between the lateral and the upstream pipe were related to the pressure change when all the flow came from the lateral. To aid in the analysis of the results of the model tests, the pressure changes for all flow 

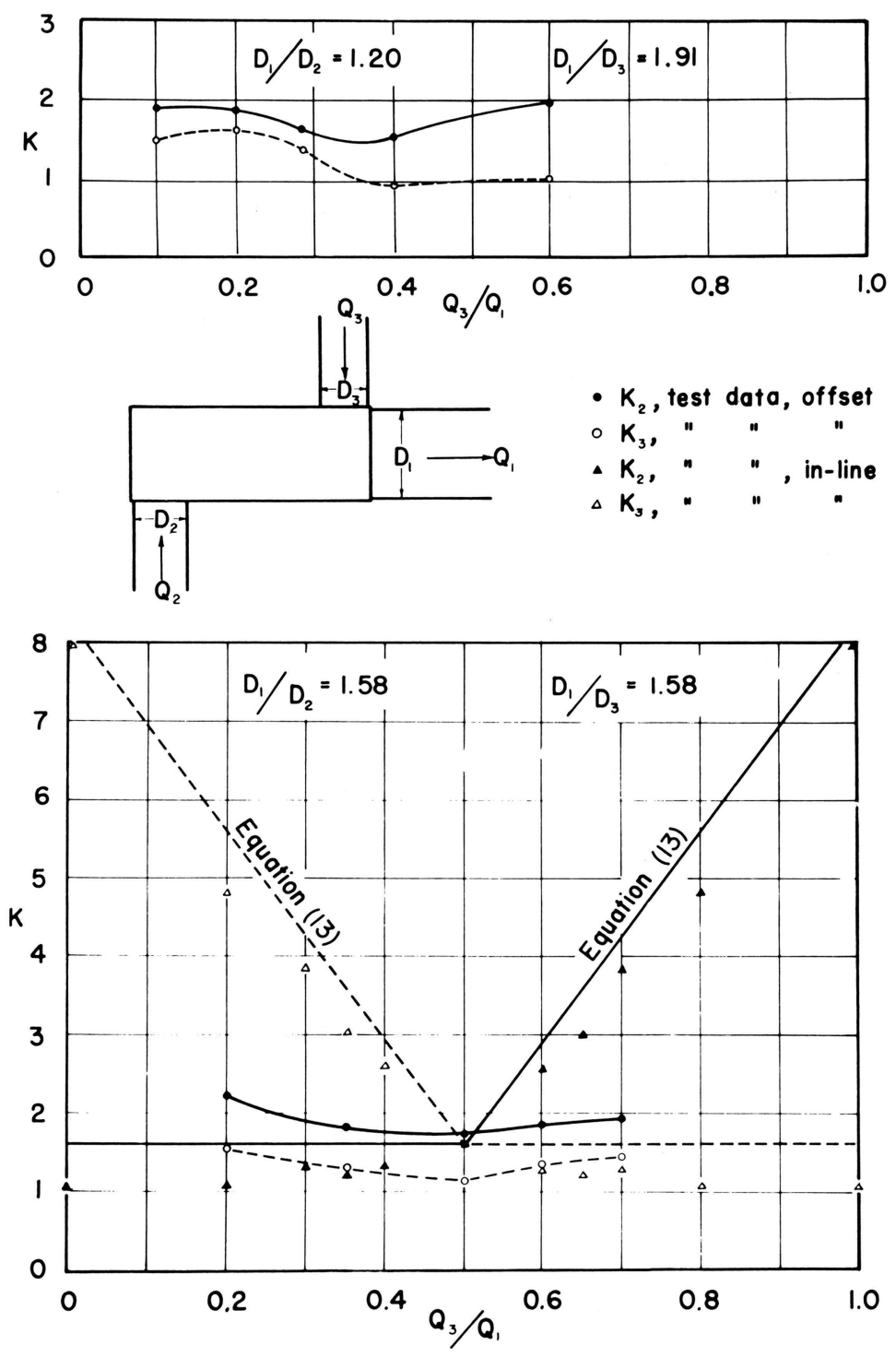

Fig. 9. Results for offset opposed lateral system. 
from the lateral were first systematized with respect to pipe size and junction size. Then a method was evolved for reduction of the pressure change coefficients from these maximum values to yield the proper values when less than the total flow was carried by the upstream in-line pipe. The analysis of pressure changes at square and round junctions is therefore divided into these two parts in the following discussion.

\section{All Flow from a $90^{\circ}$ Lateral}

Most of the tests were run using square model junctions. These square junctions had side dimensions of $6.00,6.25,7.00$, and 10.00 inches, while the round junctions tested were 6.88 and 9.88 inches in diameter. The ratio of the junction side dimension or diameter to the downstream pipe diameter ranged from 1.05 to 2.10 . This range represents the practical extent of the value of this parameter likely to be encountered in practice.

The lateral pipe size was varied so as to cover adequately the range of $\mathrm{D}_{1} / \mathrm{D}_{3}$ from 0.83 to 1.53. A few tests were run outside this range. Data for square and round junctions at which the lateral is larger than the downstream pipe were required as such cases can occur at changes of grade. The test with the extreme ratio $D_{1} / D_{3}=0.656$ was run in order to verify the contention that at very small values of $\mathrm{D}_{1} / \mathrm{D}_{3}$ the junction should behave as a large reservoir, the coefficient of pressure change thus approaching a value of 1.5. This test served to establish the validity of this reasoning.

Two series of tests were run in which the entrance to the downstream pipe was rounded on a quarter-circle arc of radius $1 / 8$ the downstream pipe diameter. All other tests employed flush, sharp-edged entrances.

The methods of testing and of determining the pressure change at the square and round junctions were the same as in the case of the rectangular junctions.

\section{Test Results}

It seems unlikely that a sound and general theoretical analysis can be devised for this arrangement. In any event the limited number of tests run did not substantiate any such analyses attempted. As a result, in lieu of an analytical method a graphical solution was devised.

Data derived from the tests on square junctions in which all the flow turned $90^{\circ}$ are presented in Fig. 10. Some of these data were modified as discussed later to fit the empirical analysis for cases in which part of the flow is carried by the upstream main. However, the data presented are in general on the conservative side wherever they do not agree completely with the tests.

The curves shown in Fig. 10 are for constant values of the ratio of the square junction side dimension to the downstream pipe diameter. They were faired in to best fit the experimental data, guided by the fact that the pressure change for the lateral must be controlled to a large extent by the momentum of the flow therein. Thus the curves should be approximately parabolic in shape, reflecting the presence in momentum considerations of the square of the pipe-diameter ratio.

To be noted in Fig. 10 is the effect of the junction size. As this is decreased relative to the downstream pipe diameter the pressure loss is also decreased appreciably. This is attributed to the fact that in a very small square junction the wall opposite the lateral is nearly flush with the downstream pipe and thus deflects the flow into this pipe. As the junction is made 

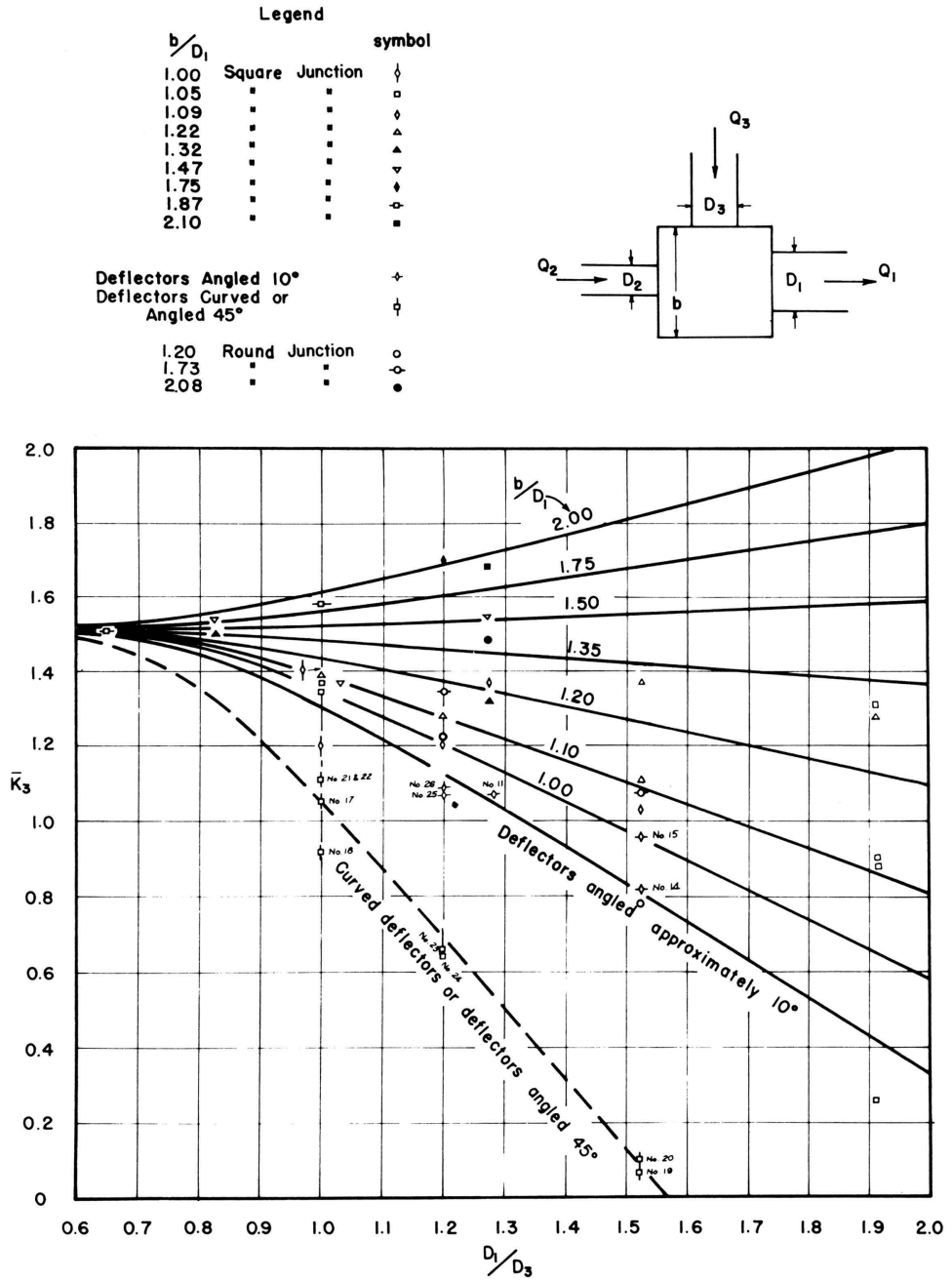

Fig. 10. Lateral coefficients for square and round junctions with all flow from lateral.

larger relatively, the effect of the wall is reduced and in such junctions the lateral flow may substantially pass the entrance to the downstream pipe, thus adversely affecting the pressure change. These contentions are further supported by tests involving deflectors. In moderately large junctions straight walls placed flush with the side of the downstream pipe and opposite the lateral exit, effecting a reduction in junction width on that one side, exhibited significantly beneficial effects.

In addition to the general effect of relative junction size on the pressure change coefficient $\overline{\mathrm{K}}_{3}$, two effects of the size of the lateral relative to the size of the downstream pipe may be noted in Fig. 10 . With small junctions, $\overline{\mathrm{K}}_{3}$ 
decreases with increasing $\mathrm{D}_{1} / \mathrm{D}_{3}$, and with large junctions $\left(\mathrm{b} / \mathrm{D}_{1}>1.50\right), \overline{\mathrm{K}}_{3}$ increases with increasing $\mathrm{D}_{1} / \mathrm{D}_{3}$.

An increase in the pressure change as the lateral pipe size was reduced was also observed in the earlier investigation of rectangular junctions with combining flow in which junctions of large dimension transverse to the downstream pipe were used. The data from these model tests aided the determination of the curves of Fig. 10 for the larger size square junctions.

Round Junctions. - The results of tests on round junctions are also included in Fig. 10. Apparently the round junction is a more efficient transition than its square counterpart under certain limited conditions. However, definite conclusions on the extent of pressure loss reductions with such junctions are not possible with only the extremely limited number of tests made. Two sets of tests with $\mathrm{D}_{1} / \mathrm{D}_{3}=1.53$ indicate a reduction in $\overline{\mathrm{K}}_{3}$ on the order of 0.6 . Two other tests with $\mathrm{D}_{1} / \mathrm{D}_{3}=1.20$ disclose a reduction in the neighborhood of 0.2 .

Deflecting Devices.-Several deflecting devices were installed in these junctions to test their effectiveness. The trend of these data is indicated in Fig. 10. It is apparent that the walls having larger deflection angles are more effective, though they do preclude flow from an upstream main.

\section{Combining Flow}

The tests involving flow through all three pipes of this configuration were continuations of the $90^{\circ}$-angle lateral pipe tests just described with the addition of an investigation of the effect of various divisions of flow between upstream main and lateral. Since it was felt that Eq. (4), derived for and applied to the rectangular junction with through and lateral flow, would be adequate for square and round junctions when most of the flow is carried by the upstream main, major attention was given situations in which most of the flow entered from the lateral.

The same general arrangement and pipe-size ratios were employed as in the cases in which all flow was carried by the lateral. The main-todownstream pipe-size ratio was generally small, but a few tests were run with upstream mains nearly as large as the downstream pipes.

No satisfactory theoretical analysis of flow through such junctions has yet been formulated. However, an entirely empirical modification of the equation for rectangular junctions-Eq. (4) - has been devised which yields very promising results. Somewhat different equations are required for the upstream and lateral coefficients, $\mathrm{K}_{2}$ and $\mathrm{K}_{3}$, respectively.

For the upstream main the equation

$$
K_{2}=\bar{K}_{2}\left[1-\left(\frac{Q_{2}}{Q_{1}} \frac{D_{1}}{D_{2}}\right)^{2}\right]
$$

is proposed, in which $\overline{\mathrm{K}}_{2}$ is the value of $\mathrm{K}_{2}$ when all the flow enters the manhole from the lateral. Values of $\overline{\mathrm{K}}_{2}$ are shown in Fig. 11.

For the lateral pipe the equation

$$
K_{3}=\bar{K}_{3}\left[1-\left(\frac{Q_{2}}{Q_{1}} \frac{D_{1}}{D_{2}}\right)^{2 D_{1} / D_{3}}\right]
$$

is proposed, in which $\overline{\mathrm{K}}_{3}$ is the value of $\mathrm{K}_{3}$ when all the flow comes from the lateral. Values of $\bar{K}_{3}$ are shown in Fig. 10 . The variable exponent was devised to reflect the fact that at large values of $D_{1} / D_{3}$ the curvature of plots of $\mathrm{K}_{3}$ vs. $\mathrm{Q}_{3} / \mathrm{Q}_{1}$ is greater than at small values. 

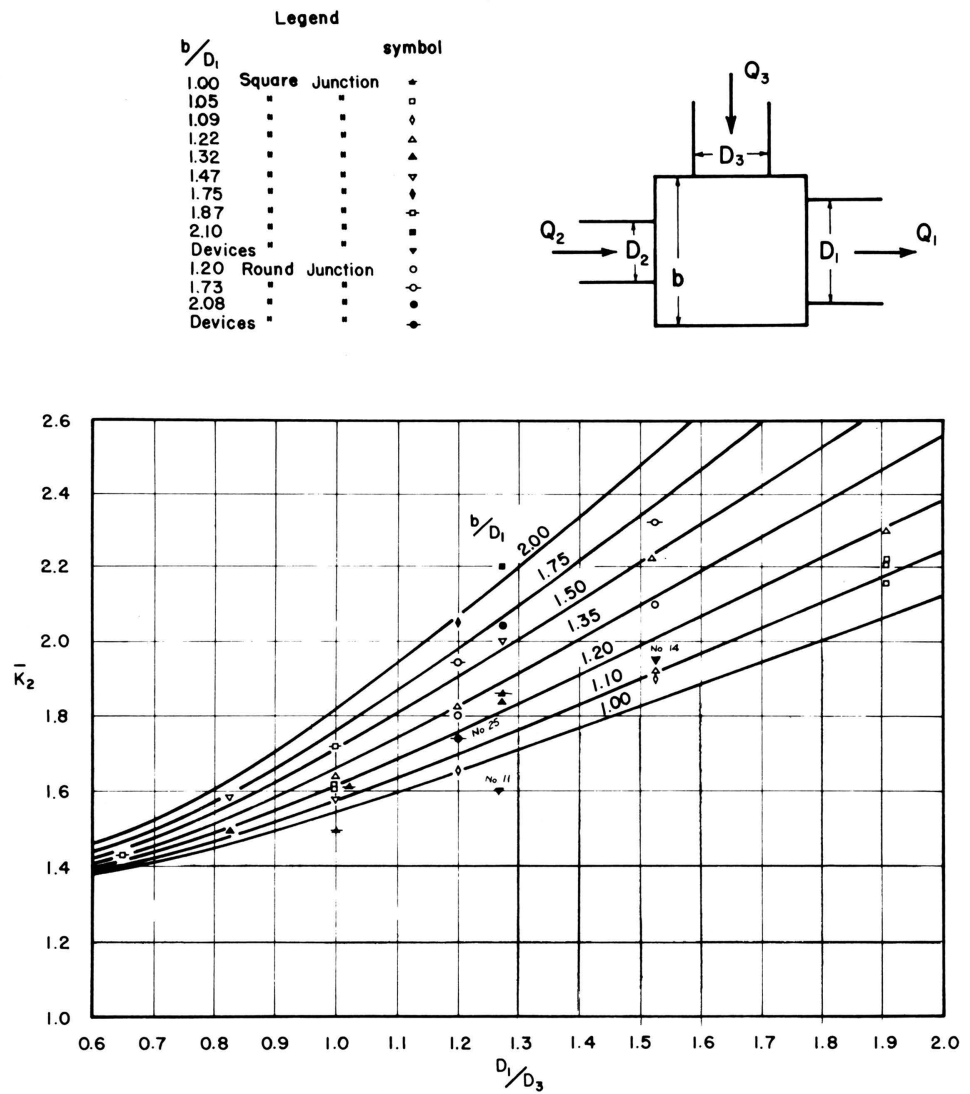

Fig. 11. Upstream main coefficients for square and round junctions with all flow from lateral.

Both of Eqs. (14) and (15) satisfy two necessary conditions. They correspond to the experimental data when $Q_{3} / Q_{1}=1$, and they have the value zero when the momentum in the upstream main equals that in the downstream main. The necessity of the second of these two conditions was established by the test results. That Eqs. (14) and (15) do indeed satisfy this requirement is evident if it is recognized that the quantity $\left(\frac{Q_{2}}{Q_{1}} \frac{D_{1}}{D_{2}}\right)$ is nothing more than the square root of the momentum ratio between the upstream and downstream mains. To obtain values of $\mathrm{K}_{2}$ and $\mathrm{K}_{3}$ for lateral discharge rates less than those prevailing at equal upstream and downstream momenta, resort must be had to Eq. (4). 

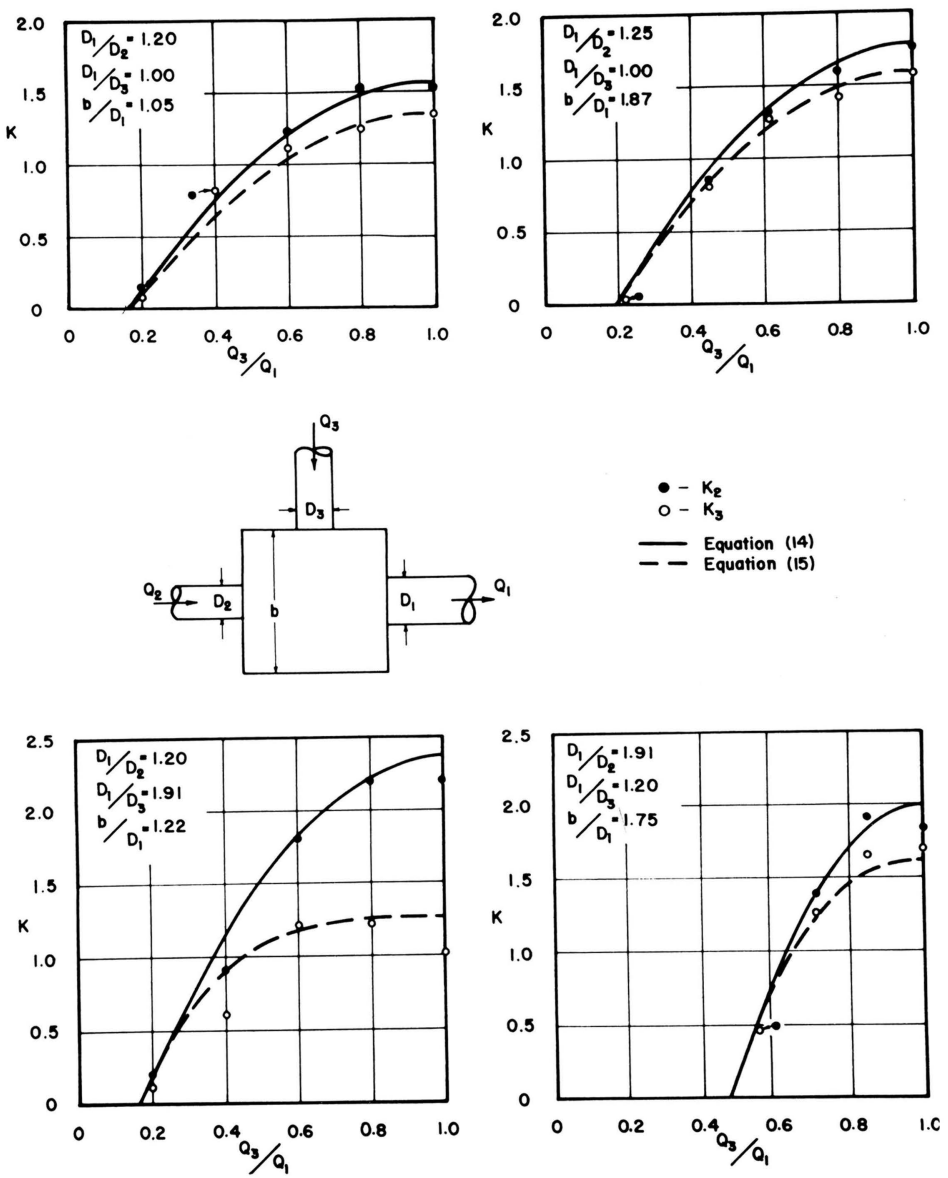

Fig. 12. Results for square junctions.

Test Results

Data for the in-line main pressure change derived from the tests on square and round junctions in which all the flow turned $90^{\circ}$ are presented in Fig. 11 . Although the in-line pipe carried no flow, it filled with water from the lateral as flow was established, and served to measure the pressure level in the model junction. Together Figs. 10 and 11 give complete data on pressure changes for conditions in which all flow turns $90^{\circ}$.

The curves shown in Fig. 11 are for constant values of the ratio of the junction side dimension or diameter to the downstream pipe diameter, as in Fig. 10. The plotted points for $\overline{\mathrm{K}}_{2}$ at $\mathrm{Q}_{3} / \mathrm{Q}_{1}=1$ in Fig. 11 are obtained by plotting $K_{2}$ against $Q_{3} / Q_{1}$ and then extending curves through the values for $Q_{3} / Q_{1}<0.85$ in accordance with Eq. (14) to obtain a corrected value for $\overline{\mathrm{K}}_{2}$ at $Q_{3} / Q_{1}=1$. The procedure of plotting points and drawing curves in Fig. 11 was similar to that described for the construction of Fig. 10.

Plots of $\mathrm{K}_{2}$ and $\mathrm{K}_{3} \mathrm{vs}$. $\mathrm{Q}_{3} / \mathrm{Q}_{1}$ from the test data revealed that both often reached maximum values with some flow from the in-line pipe rather than at 

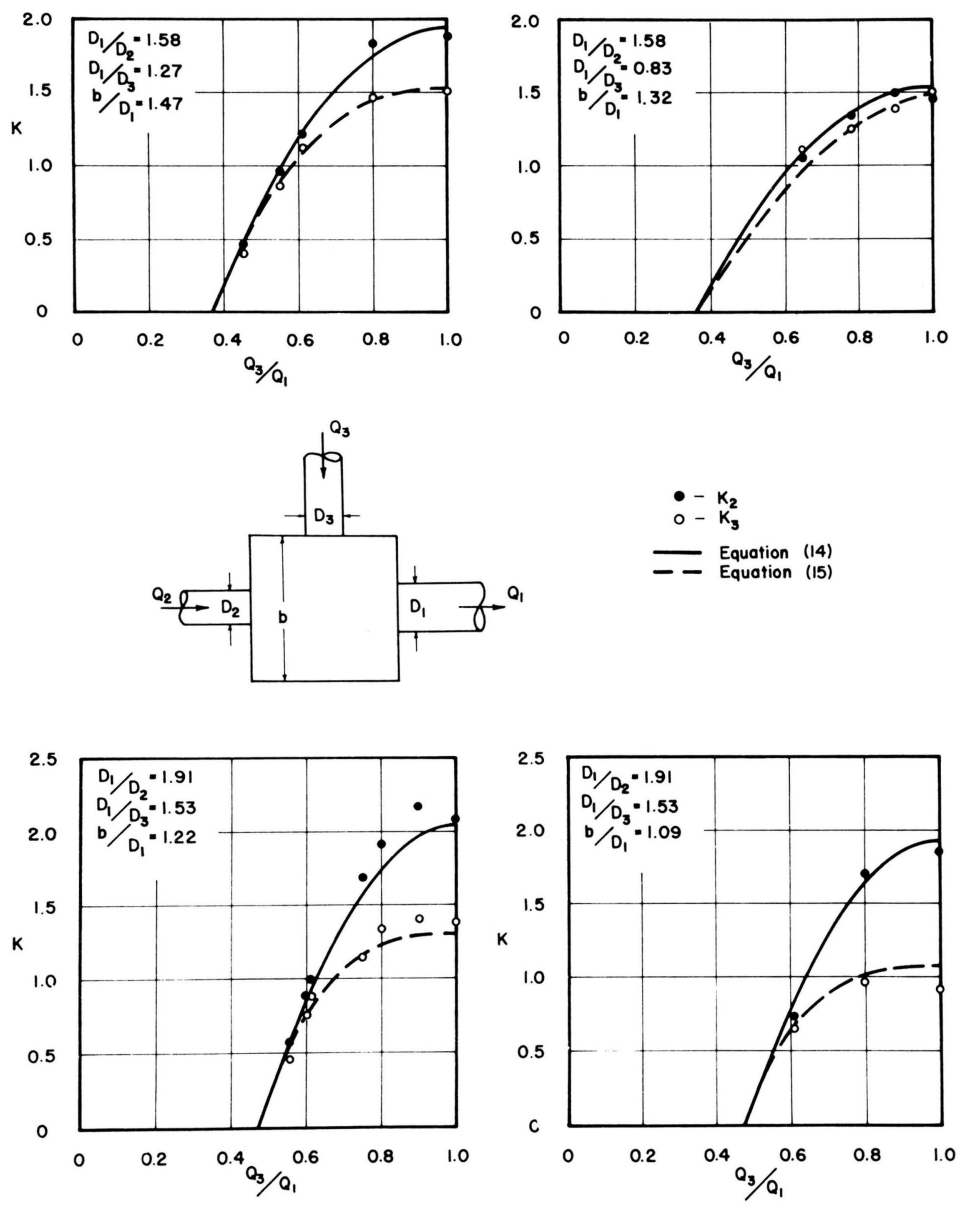

Fig. 13. Results for square junctions.

all flow from the lateral, as might be implied by Eqs. (14) and (15). However, for all flow from the lateral the values of $\mathrm{K}_{2}$ and $\mathrm{K}_{3}$ were materially less than at lesser portions of lateral flow only when the lateral pipe was significantly smaller than the outfall. Conditions of a small size lateral pipe with a high proportion of the flow are not common in field practice. Therefore the methods used to determine $\overline{\mathrm{K}}_{2}$ and $\overline{\mathrm{K}}_{3}$ when all flow enters from the lateral are considered to be justified. Any errors in evaluating pressure changes are on the side of overestimation, and become quite small in the practical range of flow divisions in the small size lateral pipes.

Several typical plots of observed values of $\mathrm{K}_{2}$ and $\mathrm{K}_{3}$ vs. $\mathrm{Q}_{3} / \mathrm{Q}_{1}$ are shown in Figs. 12-14. The curves shown represent values given by Eqs. (14) and (15) based on the $\overline{\mathrm{K}}_{3}$ and $\overline{\mathrm{K}}_{2}$ values of Fig. 10 and 11 , respectively. The curves in Fig. 14 were obtained through use of the individual values of $\overline{\mathrm{K}}_{3}$ for round junctions as given in Fig. 10 rather than from the curves, which apply strictly only to square junctions. 

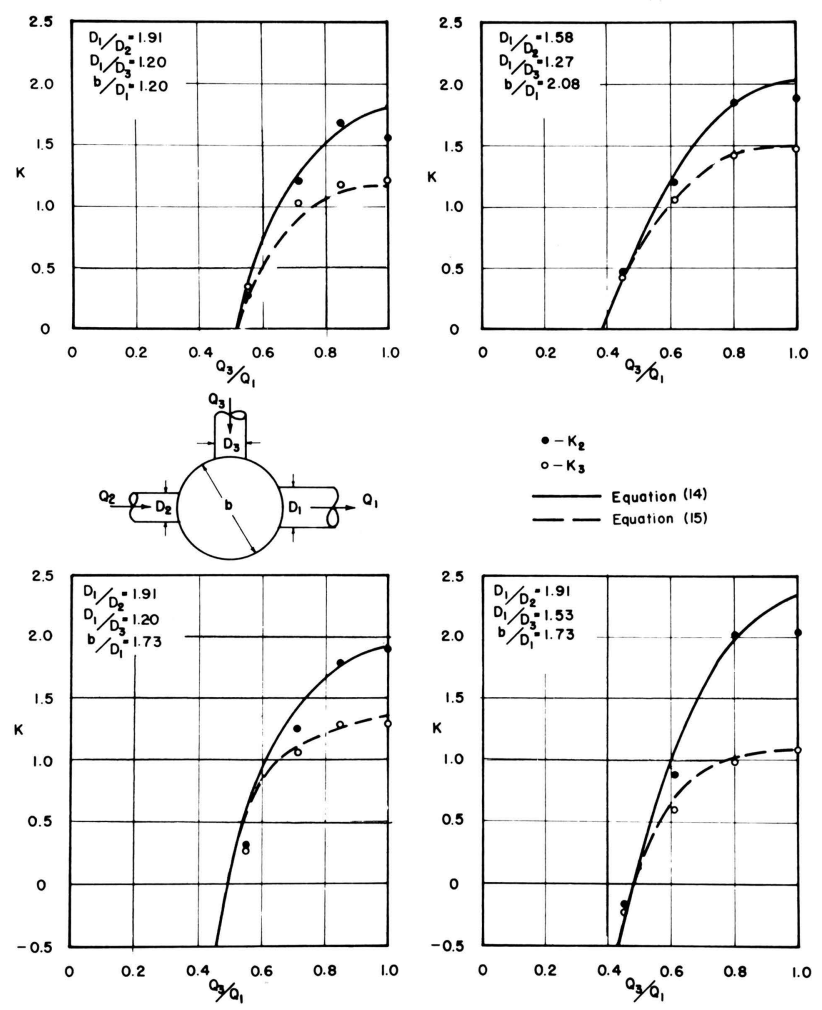

Fig. 14. Results for round junctions.

Obviously the conformance of the equations to the test data is satisfactory, even when markedly different upstream main pipe diameters are employed. This is indicated in Fig. 12 and is significant in that quite different ranges of the parameter $Q_{3} / Q_{1}$ are involved for positive values of $K_{2}$ and $K_{3}$.

It is worthy of note that the only distinction between the square and round junctions is manifested in the different values (in general lower*) of $\overline{\mathrm{K}}_{3}$ required for the latter. Otherwise, the application of Eqs. (14) and (15) is exactly the same for both shapes.

Deflecting Devices. - Several deflecting devices as illustrated in the insets in Figs. 15 and 16 were installed for the purpose of reducing pressure losses at square and round junctions. The results of the tests on these devices are also presented in the figures.

Several conclusions can immediately be drawn from these graphs and others were based on test results which are not included in Figs. 15 and 16.

Corner deflectors intended to turn the flow from the lateral and reduce its impingement on the through flow, as incorporated in Devices No. 8 and 11 (Fig. 15), were generally ineffective in reducing pressure losses. In fact Device No. 8 had an adverse effect on the lateral pressure loss for large values of $Q_{3} / Q_{1}$ due to the throttling effect at the deflector.

Rounding or shaping of the junction bottom also proved to be ineffective. As evidenced by Device No. 15 (Fig. 16), the pressure loss for the upstream main was markedly increased by the rounding when most of the flow was 

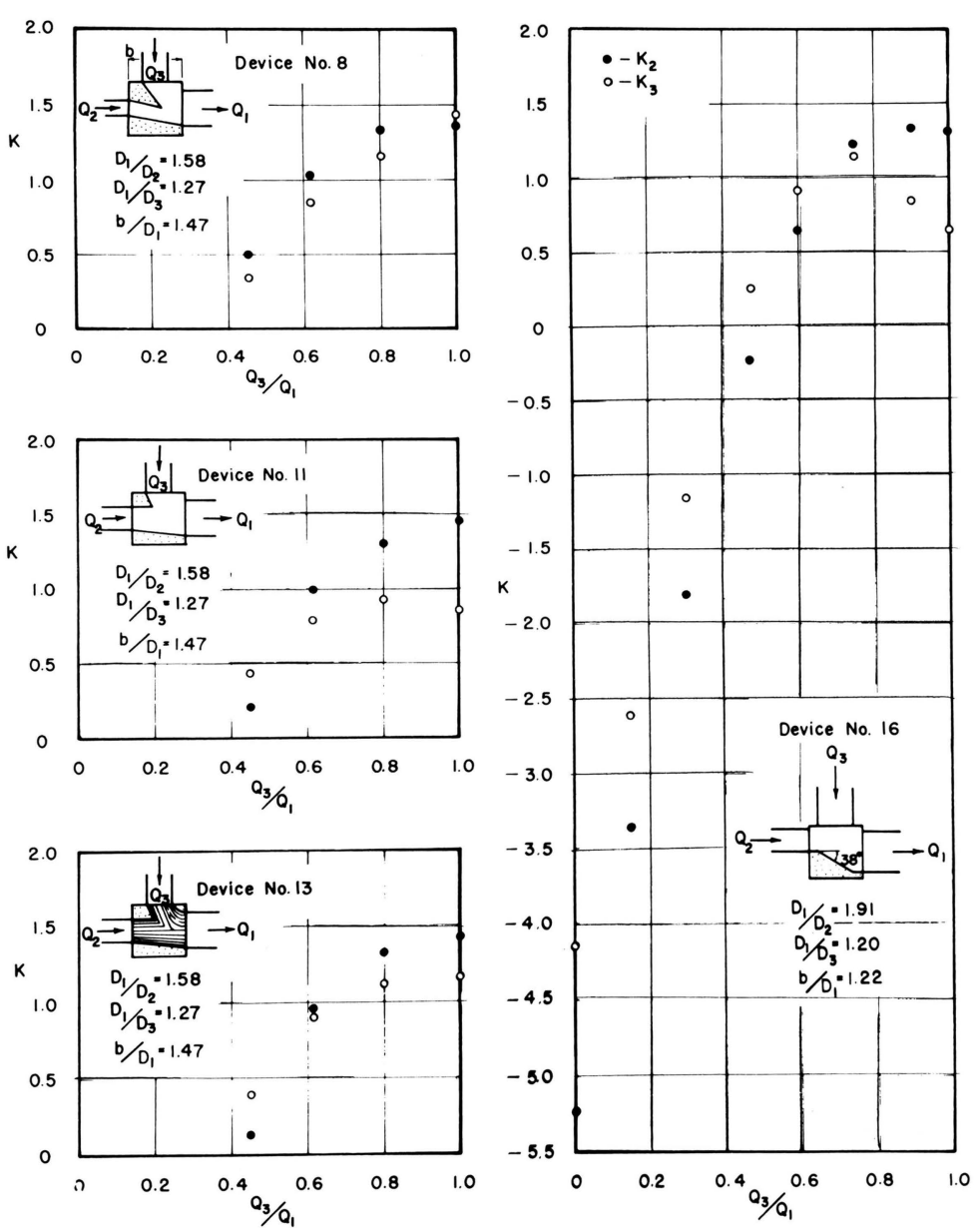

Fig. 15. Results for deflector devices in square junctions.

carried by the lateral. This was ascribed to the tendency of the rounded bottom to deflect the jet from the lateral upward thereby causing the jet to be diffused more thoroughly than it was without the rounding.

Device No. 16 (Fig. 15) exhibited some reduction in the lateral pressure loss when almost all the total flow was carried by the lateral. However, at lower values of $Q_{3} / Q_{1}$ with $V_{2} \geq V_{3}$ the loss was increased over that prevailing for the same pipe sizes without the deflector.

Simple wall-type deflectors, extending from the side of the upstream pipe to th downstream pipe and therefore at an angle of about $10^{\circ}$ with the throughpipe centerline, as exemplified by Devices No. 14 and 25, proved to be the most effective of those tested. The curves shown in Fig. 16 are plots of Eqs. (14) and (15) applied to values of $\overline{\mathrm{K}}_{3}$ and $\overline{\mathrm{K}}_{2}$ from Figs. 10 and 11 , respectively. Significant reductions in the lateral pressure loss resulted from their use without the adverse effects exhibited by the other devices previously discussed. 

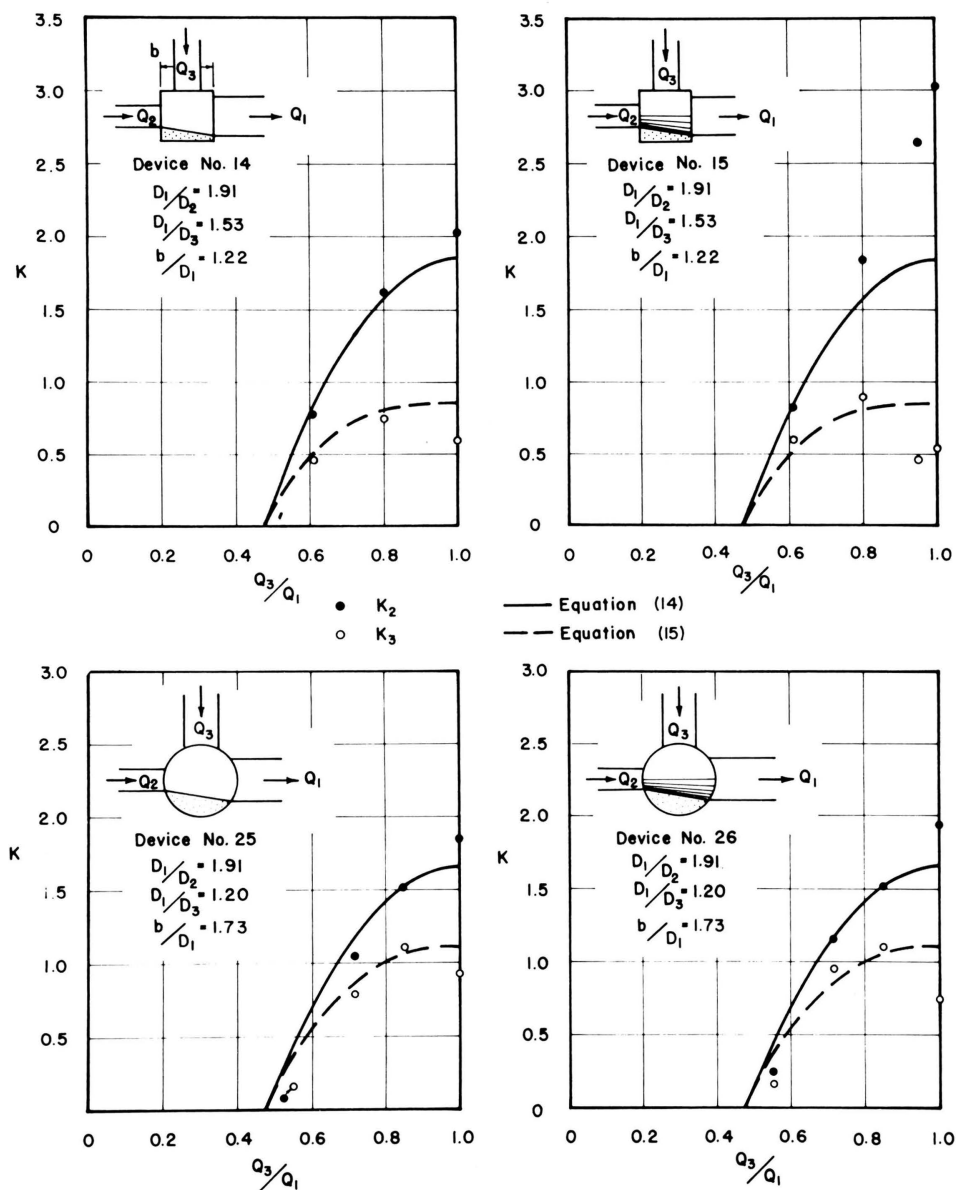

Fig. 16. Results for deflector devices in square and round junctions.

Deflector walls parallel to the downstream pipe and without bottom rounding were also tested in square junctions. These appeared to be only slightly less effective in the reduction of pressure losses than the $10^{\circ}$-angle deflectors, so long as the junction side dimension did not exceed $1.5 \mathrm{D}_{1}$. The parallel wall was less effective in the large junctions.

On the basis of the necessarily limited number of tests on wall-type deflectors at an angle to the downstream pipe, the lower two curves in Fig. 10 were added. The tests with parallel wall deflectors, also limited, served to define the curve for $b / D_{1}=1.00$ in Fig. 10. Reduction of $\mathrm{K}_{2}$ by angled deflector walls is not as great as in the case of $\mathrm{K}_{3}$. On the basis of the test data available, a curve for $\mathrm{b} / \mathrm{D}_{1}=1.00$ was added to Fig. 11 for use in defining $\overline{\mathrm{K}}_{2}$ for both zero-angle and $10^{\circ}$ deflector walls. Further reduction of $\mathrm{K}_{2}$ for the angled deflectors does not appear justified. With Figs. 10 and 11 the pressure changes in junctions with the recommended wall-type deflectors may be calculated using Eqs. (14) and (15), just as they may be for junctions without deflecting devices. 
The two series of tests in which a rounded downstream entrance was employed indicate an average reduction in $\overline{\mathrm{K}}_{3}$ of approximately 0.25 . A reduction of 0.2 may be applied to both $\overline{\mathrm{K}}_{2}$ and $\overline{\mathrm{K}}_{3}$ for purposes of design. Diminished reductions as greater portions of the flow are carried by the upstream main will result through use of Eqs. (14) and (15).

\section{SUMMARY}

In addition to the quantitative results discussed previously several qualitative conclusions of interest have been reached and are reiterated below. They apply only to junctions in pipes flowing full with the junction open to the atmosphere.

1. In expanding flow involving an upstream main aligned with a downstream main, shaping of the invert, rounding of the downstream entrance, and other similar modifications heretofore thought to be beneficial were found to be ineffective. On the other hand, projecting entrances to the downstream pipe were found not to be detrimental.

2. In the case of an in-line main and a lateral, rounding of the downstream entrance was found to be effective in reducing pressure losses when large portions of the flow were carried by the lateral. However, reentrant entrances did not exhibit adverse effects in such cases.

3. Directly-opposed laterals should not be employed when they are expected to carry flows having greatly different velocities.

4. Horizontally offsetting such opposed laterals was found to improve measurably the hydraulic characteristics of these junctions.

5. Loss-reducing devices were found to be of little benefit when combined with the offsetting of the laterals as described in 4 above.

6. In square and round junctions the pressure loss is decreased as the junction size is decreased relative to the downstream pipe size.

7. In small square and round juhctions the lateral pressure change decreases as the lateral pipe size is decreased relative to the downstream pipe size. In large junctions the reverse is true.

8. Deflecting devices in square and round junctions were found to be quite effective, particularly in those involving flow only from a lateral. Those deflectors used with three-pipe systems were somewhat more beneficial in reducing the lateral pressure loss than they were for the upstream main.

\section{ACKNOWLEDGMENTS}

The research reported in this paper was performed under a cooperative program between the Engineering Experiment Station of the University of Missouri and the Missouri Highway Department and the U. S. Bureau of Public Roads. A complete report of this project is contained in Bulletin 41 of the Engineering Experiment Station.

Messrs. C. P. Owens and L. R. Burns of the Highway Department and Carl F. Izzard, R. F. Warner, and D. E. Schneible of the Bureau of Public Roads have each contributed valuable advice and assistance. Messrs. J. E. Moulder and R. I. Theron were research engineers during the early phases of the project. The models were constructed with the assistance of Messrs. Roy Thornton and Delbert Morton. The contribution of each of these men is gratefully acknowledged. 
Fig. 1. General layout of model system.

Fig. 2. $\mathrm{K}_{2}$ for in-line system with $90^{\circ}$ lateral.

Fig. 3. $\mathrm{K}_{3}$ for in-line system with $90^{\circ}$ lateral.

Fig. 4. Effect of projecting and rounded entrances to downstream pipe.

Fig. 5. Effect of junction width for equal-size pipes.

Fig. 6. Results for two-pipe in-line system.

Fig. 7. Relative mean pressure coefficients for in-line opposed laterals.

Fig. 8. Results for in-line opposed lateral system.

Fig. 9. Results for offset opposed lateral system.

Fig. 10. Lateral coefficients for square and round junctions with all flow from lateral.

Fig. 11. Upstream main coefficients for square and round junctions with all flow from lateral.

Fig. 12. Results for square junctions.

Fig. 13. Results for square junctions.

Fig. 14. Results for round junctions.

Fig. 15. Results for deflector devices in square junctions.

Fig. 16. Results for deflector devices in square and round junctions.

\section{REFERENCES}

1. Hunter Rouse, et al., “Engineering Hydraulics”, p. 394, John Wiley and Sons, Inc., New York, 1950.

2. John L. French, "Second Progress Report on Hydraulics of Culverts; Pressure and Resistance Characteristics of A Model Pipe Culvert", pp. 56, National Bureau of Standards Report 4911, 1956.

3. John S. McNown, “Mechanics of Manifold Flow," Transactions ASCE, vol. 119, pp. 1103-1118, 1954.

4. Hunter Rouse and J. W. Howe, “Basic Mechanics of Fluids”, p. 49, John Wiley and Sons, Inc., New York, 1953.

5. Ralph W. Powell, “An Elementary Text in Hydraulics and Fluid Mechanics”, pp. 52-54, The Macmillan Company, New York, 1951.

6. Hunter Rouse, "Elementary Mechanics of Fluids", p. 198, John Wiley and Sons, Inc., New York, 1946. 




\section{PUBLICATIONS OF THE ENGINEERING REPRINT SERIES}

Copies of publications may be secured from the Director of the Engineering Experiment Station, University of Missouri. Single copies may be obtained free unless otherwise indicated until the supply is exhausted. Requests for additional copies will be considered upon further inquiry.

Reprint No.

30. The Influence of Shank Area on the Tensile Impact Strength of Bolts by John Love, Jr., General Electric Company and O. A. Pringle, Associate Professor of Mechanical Engineering. Reprinted from Transactions of the American Society of Mechanical Engineers, Vol. 78, p. 1489, October, 1956.

31. Measurement of Coating Thicknesses by Use of Pulsed Eddy Currents by Donald L. Waidelich, Associate Director, Engineering Experiment Station. Reprinted from Nondestructive Testing, Vol. 14, p. 14, MayJune, 1956.

32. Head Losses in Storm Drain Junction Boxes by Horace W. Wood, Professor of Civil Engineering. Reprinted from Highway Research Board Proceedings, Vol. 35, p. 177, 1956.

33. Stability of Laminar Flow in Curved Channels by Chia-Shun Yih, Associate Professor of Engineering Mechanics, University of Michigan and W. M. Sangster, Associate Professor of Civil Engineering, University of Missouri. Reprinted from The Philosophical Magazine, Volume 2, Eighth Series, Page 305, March 1957.

34. Viscosity of Suspensions of Spherical and Other Isodimensional Particles in Liquids by Andrew Pusheng Ting, Chemical Construction Corporation and Ralph H. Luebbers, Professor of Chemical Engineering, University of Missouri. Reprinted from the American Institute of Chemical Engineers Journal, Volume 3, Page 111, March, 1957.

35. Irrigation-Drainage-Climatology for Flat Humid Land by Harry Rubey, Professor Emeritus of Civil Engineering. Reprinted from the Proceedings of the American Society of Civil Engineers, Volume 83, Paper No. 1253, May, 1957.

36. The Impedance of a Coil Near a Conductor by D. L. Waidelich, Associate Director, Engineering Experiment Station and C. J. Renken, Jr., Argonne National Laboratory. Reprinted from the Proceedings of the National Electronics Conference, Volume 12, Page 188, 1956.

37. Automatic Control - The Fundamentals by Gladwyn Lago, Associate Professor of Electrical Engineering. Reprinted from the Proceedings of the Second Annual Conference on Automatic Control, University of Oklahoma, April 29-30, 1957, Page 9.

38. Non-Aqueous Solvent Electrochemical Systems, by G. Myron Arcand, Assistant Professor of Chemistry, and James R. Tudor, Assistant Professor of Electrical Engineering. Reprinted from Proceedings of Eleventh Annual Battery Research and Development Conference, Power Sources Division, United States Army, Signal Engineering Laboratories, Fort Monmouth, New Jersey, May 22-23, 1956, pages 16-19.

39. Compensation of Sampled-Data Systems by L. M. Benningfield, Assistant Professor of Electrical Engineering, and G. V. Lago, Associate Professor of Electrical Engineering, Reprinted from Proceedings of the National Electronics Conference, Volume XIII, Hotel Sherman, Chicago, nlinois, October 7, 8, 9, 1957, pages 888-897.

40. A. Application of the Smith Chart to the Design of Microwave Absorbing Materials by D. L. Waidelich, Professor of Electrical Engineering, University of Missouri.

B. Synthesis of Control Systems Based on an Approximation to a Third-Order System by C. R. Hausenbauer, University of Arizona, Tucson, Ariz., and G. V. Lago, Professor of Electrical Engineering, University of Missouri, Columbia, Mo. A paper presented at the AIEE Summer General Meeting and Air Transportation Conference, Buffalo, N. Y., June 22-27, 1958.

41. A. Reduction of Probe-Spacing Effect in Pulsed Eddy Current Testing by Donald L. Waidelich, Professor of Electrical Engineering.

B. Minimizing the Effect of Probe-to-Metal Spacing in Eddy Current Testing by C. J. Renken, Jr., Research Assistant, and D. L. Waidelich, Professor of Electrical Engineering.

Reprints from Symposium on Nondestructive Tests in the Field of Nuclear Energy. American Society for Testing Materials, 1958.

42. A system of Gaging Plating Thickness by R. G. Myers, Assistant Electrical Engineer, Argonne National Laboratory and D. L. Waidelich, Professor of Electrical Engineering, University of Missouri. Reprinted from Transactions of the American Institute of Electrical Engineering, Vol. 77, Part I, p. 770, 1958.

43. Network Analyzer Measurement of the Mesh Equivalent of a Complex Circuit by J. C. Hogan, Professor of Electrical Engineering, University of Missouri and V. E. Verrall, Electrical Engineer, Central mlinois Public Service Company.

44. The Design of a Single-Layer Microwave Absorbing Material by D. L. Waidelich, Professor of Electrical Engineering, University of Missouri. Reprinted from Volume XIV, Proceedings of the National Electronics Conference, Hotel Sherman, Chicago, mlinois, October 13, 14, 15, 1958.

45. Pressure Changes at Open Junctions in Conduits by William M. Sangster, Associate Professor of Civil Engineering, University of Missouri; Horace W. Wood, Professor and Chairman of Civil Engineering, University of Missouri; Ernest T. Smerdon, Instructor in Civil Engineering, University of Missouri; and Herbert G. Bossy, Highway Research Engineer, U.S. Bureau of Public Roads, Washington, D.C. Reprinted from Journal of the Hydraulics Division, Proceedings of the American Society of Civil Engineers, 2057, June, 1959, HY6.

*Out of Print. 


\section{The University of Missouri SCHOOLS AND COLLEGES}

College of Arts and Science

SCHOOL OF SOCIAL WORK

Division of Agricultural SCIENCES

College of Agriculture

SCHOOL OF VeTERINARY MEdicine

SCHOOL OF FORESTRY

SCHOOL OF Business AND Public Administration

COLlege of Education

College OF ENGINEERING

ENGINEERING EXPERIMENT STATION

GRADUATE SCHOOL

SCHOOL OF JOURNALISM

SCHOOL OF LAW

SCHOOL OF MEDICINE

SCHOOL OF NURSING 


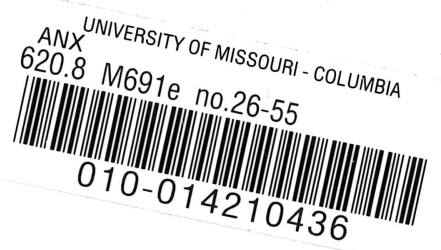

620.8

M69IE

COP. 3

26-55

D63616 
University of Missouri Libraries

University of Missouri

MU Engineering Experiment Station Series

Local Identifier

Sangster1959

Capture information
Date captured
2019 January

Scanner manufacturer Fujitsu

Scanner model

fi-7460

Scanning software

ScandAll PRO V. 2.1.5 Premium

Optical resolution $600 \mathrm{dpi}$

Color settings

File types

Notes Grayscale, 8 bit; Color, 24 bit Tiff

Barcode page scanned on Ricoh MP C4503

Source information

Format

Content type

Barcode

Notes
Book

Text

010-014210436

Digitized duplicate copy not retained in collection.

Derivatives - Access copy

Compression

Editing software

Resolution

Color

File types

Notes
LZW

Adobe Photoshop

$600 \mathrm{dpi}$

Grayscale, 8 bit; Color, 24 bit Tiffs converted to pdf Pages without color converted to gratscale. Greyscale pages cropped and canvassed. Noise removed from background and text darkened. Color pages cropped. 